$$
\text { LA-SUB--95-19Y }
$$

\title{
RESULTS OF ALUMINIUM COMPOSITE BEHAVIOUR RESEARCH UNDER DYNAMIC LOADS
}

(2 stage of contract 0002 P 0004-95 task 3)

Contract manager,

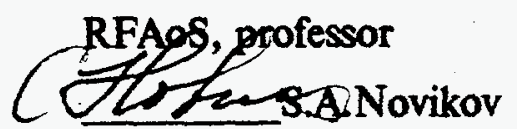

Principle investigator, DPL
Aaut -Yu.V.Bat'kor

DISTRBBUTION OF THIS DOCUMENT IS UNLMITED

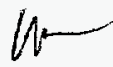




\section{DISCLAIMER}

This report was prepared as an account of work sponsored by an agency of the United States Government. Neither the United States Government nor any agency thereof, nor any of their employees, make any warranty, express or implied, or assumes any legal liability or responsibility for the accuracy, completeness, or usefulness of any information, apparatus, product, or process disclosed, or represents that its use would not infringe privately owned rights. Reference herein to any specific commercial product, process, or service by trade name, trademark, manufacturer, or otherwise does not necessarily constitute or imply its endorsement, recommendation, or favoring by the United States Government or any agency thereof. The views and opinions of authors expressed herein do not necessarily state or reflect those of the United States Government or any agency thereof. 


\section{DISCLAIMER}

Portions of this document may be illegible in electronic image products. Images are produced from the best available original document. 


\section{ABSTRACT}

Report is prepared in accordance with stage 3.3 of subcontract $0002 \mathrm{P}$ 0004-95, task 003, between Russia Federal Nuclear Center - All-Russia NII of Experimental Physics (RFNC-VNIIEF) and Los-Alamos National Laboratory (LANL) "Study of Aluminium Composite Plastic Deformation Resistance and Destruction under Dynamic Loads".

The report presents the results of physical and mechanical property study for aluminium composite A 359 DURAL from San-Diego under dynamic and shock-wave loads.

The report was prepared by a team of VNIIEF specialists: S.A.Novikov, Yu.V.Bat 'kov, V.A.Pushkov, A.B.Glushak, V.A.Ogorodnikov, M.V.Zhemokletov, V.I.Skokov, N.D.Fishman, A.N.Lebedev.

English translation was done by Panevkina E.I. 


\section{CONTENTS}

INTRODUCTION

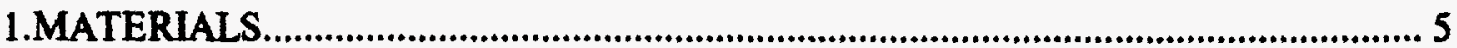

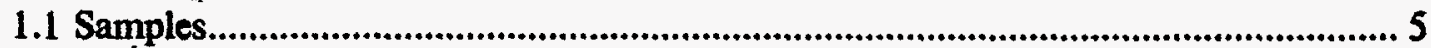

1.2 Macro- and microstructure, microhardness ........................................................... 5

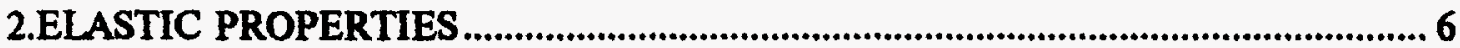

3. STRESS-STRAIN DIAGRAMS.......................................................................... 7

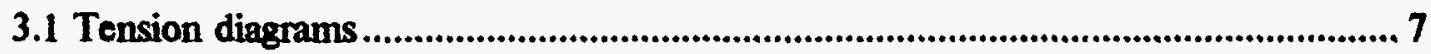

3.2 Compression diagrams ................................................................................................ 8

4. CRACK RESISTANCE ...................................................................................... 9

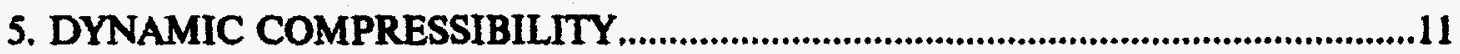

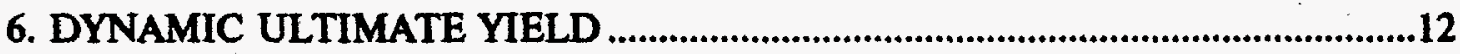

7. SHEAR STRENGTH

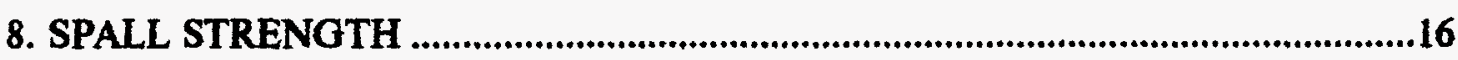

8.1 Plate impact............................................................................................................16

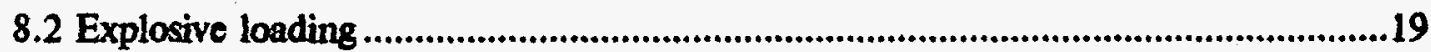

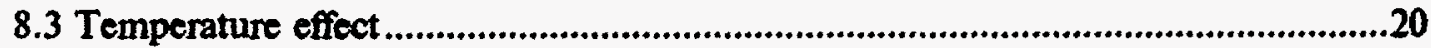

8.4 Metallographic study............................................................................................20

CONCLUSIONS.....................................................................................................22

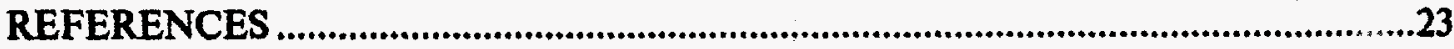




\section{INTRODUCTION}

According to task 003 of subcontract 0002 P 0004-95 between RFNCVNIIEF (Russia) and LANL (USA). "Investigation of destruction and resistance to plastic deformation of composite materials under dynamic loads". VNIIEF does the research of aluminium composite $(\mathrm{AL}+20 \% \mathrm{SiC})$ behaviour which is delivered by LANL, under dynamic and quasistatic loads.

At stage 3.2 (task 1), report [1] was prepared which gives the description of the techniques, facilities and devices used by VNIIEF to study the material behaviour. For each technique the results of typical composite material research were presented which illustrate its capabilities. Three blanks of aluminium composite A359 DURAL from San-Diego were obtained in February 1995 which total weight was $63 \mathrm{~kg}$; and according to the prepared drawings the samples were fabricated for tests.

This report prepared according to task 3.3 (stage 2) of the contract contains the research results of physical and mechanical properties of the aluminium composite under dynamic and shock-wave loads. 


\section{MATERIALS}

\subsection{SAMPLES}

The efforts were aimed at the study of LANL delivered aluminium composite - alloy A 359 of DURAL company from San-Diego which is aluminium alloy $\mathrm{A} 356$ modified with high $\mathrm{Si}$ content. Stichiometric composition of aluminium composite (AC): base-Al; $8.5-9.5 \% \mathrm{Si} ; 0.02 \% \mathrm{Fe} ; 0.02 \% \mathrm{Cu} ; 0.1 \%$ $\mathrm{Mn} ; 0.45-0.6 \% \mathrm{Mg}$; $0.02 \% \mathrm{Ti} ; 0.2 \% \mathrm{Sn}$.

The research samples of 10 types were fabricated in VNIIEF according to specially developed drawings A0311-L233.000 out of three blanks $\varnothing 180 \mathrm{~mm}$ and $360 \mathrm{~mm}, 320 \mathrm{~mm}, 360 \mathrm{~mm}$ long. Figure 1 shows the geometry of blank cutting for sample fabrication (along and across the blank axis). Figure 2 presents the pictures of the samples to study the AC dynamic properties.

After the samples were fabricated of LANL blanks, they were heated to $530^{\circ} \mathrm{C}$ for 8 hours and cooled down in the hot water and subsequently cooled in the air (regime T-6). The measured sample density was $\rho_{0}=2.760+2.779 \mathrm{~g} / \mathrm{cm}^{3}$.

\subsection{MACRO- AND MICROSTRUCTURE, MICROHARDNESS}

The delivered aluminium composite (AC) was metallographically studied with witness-samples cut out of one blank as received and after thermal treatment. Figure 3 presents the cutting geometry for the witness-samples for the studies (the sample surfaces for microsections to be made are cross-hatched). The metallographic study included the analysis of macro- and microstructures and identification of material microhardness in the witness-samples on the surfaces marked in fig. 3 and by the technique presented in ref.[1]. The aluminium composite as received and after thermal treatment has the structure of the aluminium base comprising dendrites of the solid solution of aluminium and silicon (of maximum 1.65\% silicon contents according to Al-Si state diagram) and aluminium-silicon eutectics (of $12.7 \%$ silicon contents according to Al-Si state diagram) with sprinkled $\mathrm{SiC}$ particles (fig.4a). The material is characterized by macro- and microheterogenuity, namely, uneven SiC particle distribution in the aluminium base (fig.4b). Almost in all studied witness-samples as received (11 samples) and after thermal treatment (11 samples) large zones are seen which completely lack the carbide constituent (in figs. 5a, b-dark areas, in figs. 5c and $4 \mathrm{~b}$-light areas). $\mathrm{SiC}$ particles are $0.014 \mathrm{~mm}$ lange in average, however big particles of $0.16 \mathrm{~mm}$ are also observed (fig. $4 \mathrm{c}$ ).

The microhardness of the aluminium base as received is $103.6 \mathrm{~kg} / \mathrm{mm}^{2}$, in average, and after thermal treatment $-123.2 \mathrm{~kg} / \mathrm{mm}^{2}$, i.e. its slight increase is observed as a result of thermal treatment, by $19.6 \mathrm{~kg} / \mathrm{mm}^{2}$ approximately. The difference between the microhardness of the solid aluminium solution with silicon is negligible. The microhardness of silicon carbide particles as received is $3023 \mathrm{~kg} / \mathrm{mm}^{2}$, in average, and after thermal treatment $-3426 \mathrm{~kg} / \mathrm{mm}^{2}$, i.e. its increase is also observed as a result of thermal treatment by $403 \mathrm{~kg} / \mathrm{mm}^{2}$ in average. 


\section{ELASTIC PROPERTIES}

Pulsed ultrasonic method similar to the described in ref.[2] was used to measure the velocities of elastic ware and elastic modulus propagation for the aluminium composite.

According to this method, thin piezoelectrical converters were connected to the ends of a cylindrical sample: an emmiter and a receiver of short ultrasonic pulses. The time intervals were measured from the beginning of emission till different ultrasonic ware pulse arrival at the receiver. Based on the measured times, the velocities of longitudinal and transversal elastic wave propagation in the sample material were calculated. Elastic moduli were calculated based on the obtained velocities and sample densities.

To do the measurements, 3 cylindrical samples $10 \mathrm{~mm}$ in diameter and $25 \mathrm{~mm}$ high were prepared and cut along the blank axis. Table 1 shows the resultant measured velocities of elastic waves $\mathrm{C}_{1}$ (longitudinal), $\mathrm{Ct}$ (transversal) and calculated elastic moduli at confidential probability $\mathrm{P}=0.95$.

Table 1.

Elastic Wave Velocities and Elastic Moduli for Aluminium Composites

\begin{tabular}{|l|c|c|}
\hline \multicolumn{1}{|c|}{ Name } & Value & $\begin{array}{c}\text { Confidenti } \\
\text { al } \\
\text { interval, } \pm\end{array}$ \\
\hline Density $\rho_{0}, g / \mathrm{cm}^{3}$ & 2.761 & 0.001 \\
\hline Longitudinal wave velocity $\mathrm{C}_{1}, \mathrm{~km} / \mathrm{s}$ & 7.16 & 0.04 \\
\hline Transversal wave velocity $\mathrm{Ct}, \mathrm{km} / \mathrm{s}$ & 3.767 & 0.015 \\
\hline Plane wave modulus, $\rho \mathrm{C}_{1}^{2}, \mathrm{GPa}$ & 141.5 & 1.7 \\
\hline Shear modulus $\mathrm{G}, \mathrm{GPa}$ & 39.2 & 0.3 \\
\hline Bulk compression modulus $\mathrm{K}, \mathrm{GPa}$ & 89.2 & 1.3 \\
\hline Young's modulus $\mathrm{E}, \mathrm{GPa}$ & 102.6 & 0.9 \\
\hline Poisson's coefficient $\nu$ & 0.3083 & 0.0012 \\
\hline Acoustic resistance $\rho \mathrm{C}{ }_{1}$ & 19.77 & 0.12 \\
\hline Sound velocity $\mathrm{C}_{0}, \mathrm{~km} / \mathrm{s}$ & 5.68 & 0.04 \\
\hline
\end{tabular}




\section{STRESS-STRAIN DIAGRAMS}

With the techniques described in ref.[1] the dynamic mechanical properties of the aluminium composite were studied:

- tension diagrams at $\mathrm{T}=25^{\circ} \mathrm{C}$ and strain rates $\dot{\varepsilon}=200-260 \mathrm{~s}^{-1}$ (4 tests);

- compression diagrams at $\mathrm{T}=-50,25,100,300^{\circ} \mathrm{C}$ and strain rates $\dot{\varepsilon}=200$ $500 \mathrm{~s}^{-1}$ (13 tests).

\subsection{TENSION DIAGRAMS}

The samples of reverse type in the form of a thimble [1] were tested which had a working length of $8 \mathrm{~mm}$, four through grooves and $40 \mathrm{~mm}^{2}$ working crosssection. The samples were cut out of a cylindrical blank perpendicular to its axis (direction 1) and parallel to its axis (direction 2).

Figure $6 a$ gives a typical tension diagrams $\delta-\varepsilon$ for the aluminium composite at $25^{\circ} \mathrm{C}$ and $200 \mathrm{~s}^{-1}$ strain rate. Here, also in fig. $1 \mathrm{~b}$ the strain relationship $\varepsilon=\varepsilon(t)$ in this test is shown which was used to determine strain rate $\dot{\varepsilon}$. As it is seen from fig. $6 \mathrm{~b}$, during the first $\sim 15 \mathrm{~ms}$ the strain rate grows from zero to its value $\dot{\varepsilon}=$ const $=200 \mathrm{~s}^{-1}$. The similar picture was seen in other tests.

As the tests have shown, the aluminium composite at $25^{\circ} \mathrm{C}$ resists slightly to the dynamic tension and destructs frangibly via normal detachment. Providiry, in all tests the destruction took place at $\sim 0.2 \%$ deformations. Fragile destruction of the samples resulted in the fact that yield strengths $\sigma_{0.1}$ and $\sigma_{0.2}$ were almost equal and corresponded to ultimate strength $\sigma_{\mathrm{mm}}$ in each individual test.

Table 2 presents the test results at $25^{\circ} \mathrm{C}$.

Table 2.

\begin{tabular}{|c|c|c|c|c|c|}
\hline $\mathrm{N}$ test & $\mathrm{T},{ }^{\circ} \mathrm{C}$ & $\dot{\varepsilon}, s^{-1}$ & $\sigma_{0.2}, \mathrm{MPa}$ & $\sigma_{\mathrm{km}}, \mathrm{MPa}$ & $\begin{array}{c}\text { Cut } \\
\text { direction }\end{array}$ \\
\hline 1 & \multirow{4}{*}{25} & 200 & 260 & 260 & 1 \\
\hline 2 & & 260 & 240 & 240 & 1 \\
\hline 3 & & 240 & 220 & 220 & 1 \\
\hline 4 & & 250 & 280 & 280 & 2 \\
\hline
\end{tabular}




\subsection{COMPRESSION DIAGRAMS}

The samples in the cylindrical geometry $8 \mathrm{~mm}$ in diameter, $8 \mathrm{~mm}$ long, $50 \mathrm{~mm}^{2}$ working section were tested. The samples were cut out of the blank both in direction 1 and direction 2 (see subsection 3.1).

Figure 7 gives a typical compression diagram $\sigma-\varepsilon$ for the aluminium at $25^{\circ} \mathrm{C}$ and strain rate $39 \mathrm{~s}^{-1}$. Here also, in fig. $7 \mathrm{~b}$ strain relationship $\varepsilon=\varepsilon(\mathrm{t})$ is shown for this test, which demonstrates that the test strain rate was constant ( $\dot{\varepsilon}=$ const) as a whole. Diagram $\sigma-\varepsilon$ shows that in the plastic section of the diagram a considerable strain hardening appears.

Table 3 presents the results of all tests at $T=-50-+300^{\circ} \mathrm{C}$. Here, except the temperature, the test numbers are shown as well as strain rate $\dot{\varepsilon}$, ultimate strength $\sigma_{0.2}$ and the direction of sample cut out of the blank (see subsection 3.1).

Table 3.

\begin{tabular}{|c|c|c|c|c|}
\hline $\mathbf{N}$ test & $\overline{\mathrm{T},{ }^{0} \mathrm{C}}$ & $\dot{\varepsilon}, \mathrm{s}^{-1}$ & $\sigma_{0.2}, \mathrm{MPa}$ & $\begin{array}{c}\text { Cut } \\
\text { direction }\end{array}$ \\
\hline$\overline{1}$ & \multirow{3}{*}{-50} & 320 & 370 & 2 \\
\hline 2 & & 460 & 380 & $\overline{2}$ \\
\hline 3 & & 300 & 450 & 2 \\
\hline 4 & \multirow{4}{*}{25} & 390 & 425 & 1 \\
\hline 5 & & 320 & 375 & 1 \\
\hline 6 & & 340 & 370 & 1 \\
\hline 7 & & 310 & 385 & 2 \\
\hline 8 & \multirow{3}{*}{100} & 340 & 330 & 1 \\
\hline 9 & & 380 & 290 & 1 \\
\hline 10 & & 390 & 340 & 2 \\
\hline 11 & \multirow{3}{*}{300} & 370 & 260 & 2 \\
\hline 12 & & 200 & 270 & 2 \\
\hline 13 & & 500 & 330 & 2 \\
\hline
\end{tabular}




\section{CRACK RESISTANCE}

Crack resistance study was done with technique [1] at $\mathrm{T}=-50,25,100$, $300^{\circ} \mathrm{C}$ and relative load rates $\overline{\mathrm{V}}=(0.63-1.40)^{*} 10^{4} \mathrm{~s}^{-1}$ (13 tests).

Plane samples were tested with a wedgeshape cut, $24 \mathrm{~mm}$ wide, $20 \mathrm{~mm}$ high, $14 \mathrm{~mm}$ thick and of $196 \mathrm{~mm}^{2}$ nominal cross-section. The samples were cut both in direction 1 and direction 2 (see subsection 3.1).

Figure 8 presents typical P- $\Delta$ diagram for the aluminium composite at $25^{\circ} \mathrm{C}$ and relative load rate $\overline{\mathrm{V}}=1.40^{*} 10^{4} \mathrm{~s}^{-1}$. Magnitudes of dynamic crack resistance $K_{\text {ld }}$ were derived from the value of critical force $P_{c}$. The magnitude of $P_{c}$ was taken from P- $\Delta$ diagram in the point of diagram crossing with a straight line which slope tangent is by $5 \%$ smaller than the slope tangent of the initial section of the diagram. Providing, in the resultant $P-\Delta$ diagrams relation $P_{\max } / P_{c}<1.1$ was met $\left(P_{\max }-\right.$ maximal load in the diagram) that is one of the conditions of test correctness [2].

We could not manage to develop initial cracks in the samples because the aluminium composite is of considerable brittleness. In the attempts to create an initial crack the sample was either broken in two halves or a rather long crack was formed that did not allow to conduct the tests correctly and to define $\mathbf{K}_{1 d}$ magnitude. So, the tests were accomplished with the samples of no initial cracks. Prior to the tests a colibration function $Y$ was determined for the polymetyl methacrylate (PMMA) samples with known $K_{1 d}$, including the samples without initial cracks. The samples of PMMA were identical in size to the samples of aluminium composite and for their tests the same scheme of force applications was employed. So, calibration function Y obtained for PMMA samples could be used also for the aluminium composite samples.

Table 4 given the results of all tests at $T=-50-+300^{\circ} \mathrm{C}$. Here, except the temperature the test members are shown as well as the values of relative load rate $\dot{\mathrm{V}}$, dynamic crack resistance $K_{1 d}$ and the direction of sample cut of the blank (see subsection 3.1).

Table 4.

\begin{tabular}{|c|c|c|c|c|}
\hline $\mathrm{N}$ test & $\mathrm{T},{ }^{0} \mathrm{C}$ & $\dot{\mathrm{V}}, \mathrm{s}^{-1} \cdot$ & $\begin{array}{c}\mathrm{K}_{\mathrm{ld}}, \mathrm{MPa}^{*} \\
\mathrm{~m}^{1 / 2}\end{array}$ & $\begin{array}{c}\text { Cut } \\
\text { direction }\end{array}$ \\
\hline 1 & \multirow{3}{*}{-50} & $0.98 * 10^{4}$ & 10.0 & 2 \\
\hline 2 & & $1.04 * 10^{4}$ & 9.8 & 2 \\
\hline 3 & & $0.91 * 10^{4}$ & 10.5 & 2 \\
\hline
\end{tabular}




\begin{tabular}{|c|c|c|c|c|}
\hline 4 & \multirow[b]{2}{*}{25} & $1.20 * 10^{4}$ & 10.4 & 1 \\
\hline 5 & & $1.40^{*} 10^{4}$ & 10.8 & 1 \\
\hline 6 & & $1.14^{*} 10^{4}$ & 9.8 & 2 \\
\hline 7 & & $1.00 * 10^{4}$ & 10.5 & $\overline{2}$ \\
\hline 8 & \multirow{3}{*}{100} & $1.10^{*} 10^{4}$ & 16.2 & 2 \\
\hline 9 & & $1.20^{*} * 10^{4}$ & 16.5 & 2 \\
\hline 10 & & $1.30 * 10^{4}$ & 17.4 & 2 \\
\hline 11 & \multirow{3}{*}{300} & $0.63 * 10^{4}$ & 38.4 & 2 \\
\hline$\overline{12}$ & & $0.70^{*} 10^{4}$ & 40.5 & 2 \\
\hline 13 & & $0.64 * 10^{4}$ & 41.2 & $\overline{2}$ \\
\hline
\end{tabular}

Let us note that the first batch of test samples was cut of the blank in direction 1. Partially these samples were spent in the attempts to get initial cracks and to develop the loading modes. Later, the samples cut in direction 2 were delivered for tests. So, with the limited number of the first samples the crack resistance tests of the composite cut in various directions were conducted only at $25^{\circ} \mathrm{C}$. The tests at $\mathrm{T}=50,100,300^{\circ} \mathrm{C}$ were done with the samples cut out of the blank only in direction 2 .

The tests showed that the aluminium composite is of low crack resistance and at the noted temperatures it is destructed frangily. Thus, at $25^{\circ} \mathrm{C}$ and $\overline{\mathrm{V}}=(1.0-1.4)^{*} 10^{4} \mathrm{~s}^{-1}$ average value $\mathrm{K}_{1 \mathrm{~d}}$ constitutes $0.4 \mathrm{MPa}^{*} \mathrm{~m}^{1 / 2}$. 


\section{DYNAMIC COMPRESSIBILITY}

To obtain the data on dynamic compressibility we used an impedance matching method [4]. According to this method the studied samples were placed in the way of shock wave propagation behind the metal shields of known shock adiabats. Shock wave strength was varied with explosive throwing systems accelerating metal impactors to different velocities. In the experiments, shock wave velocities $U_{s}$ were measured in the studied samples. Other characteristics: shock compression pressure $P$, mass velocity of the substance motion behind the wave front $U_{p}$, specific density $\rho$ and volume $V$ - were calculated based on $U_{s}$ values and shock wave parameters known from special experiments in the shields, assuming the pressures and mass velocities are equal at the shield - sample interface and accounting the laws of mass and momentum conservation. The expansion isentropes of the copper and aluminium shields in $P-U_{p}$ coordinates were identified with the mirror reflections of shock adiabats. Copper and aluminium shock adiabats were taken in the form of linear $U_{s}-U_{p}$ relations [5]:

$$
\begin{array}{ll}
\mathrm{U}_{\mathrm{s}}=3.915+1.495 \mathrm{U}_{\mathrm{p}} & (\text { for } \mathrm{Cu}) \\
\mathrm{U}_{\mathrm{s}}=5.33+1.356 \mathrm{U}_{\mathrm{p}} & \text { (for } \mathrm{Al})
\end{array}
$$

Electrocontact and piezoceramic ganges placed at different sample levels were used to record the shock wave velocities in the samples [6]. The samples of $\rho_{0}=2.78 \mathrm{~g} / \mathrm{cm}^{3}$ density were fabricated in the form of pellets $12 \mathrm{~mm}$ in diameter and $3-4 \mathrm{~mm}$ high.

The experiment results are shown in table 5 which also presents the shield materials and mass velocities $U_{p}$ in them. The table values of wave velocities $U_{s}$ correspond to the average result of 4-5 independent experiments.

Graphically the obtained data are shown in $U_{s}-U_{p}$ diagram (fig.9) where they are described by the linear relation:

$$
\mathrm{U}_{\mathrm{s}}=5.54+1.356 \mathrm{U}_{\mathrm{p}}, \mathrm{km} / \mathrm{s}
$$

Table 5.

\begin{tabular}{|c|c|c|c|c|c|c|}
\hline \multicolumn{4}{|c|}{ Loading device } & \multicolumn{4}{c|}{ Shock wave parameters in sample } \\
\hline & $\mathrm{U}_{\mathrm{p}}, \mathrm{km} / \mathrm{s}$ & $\mathrm{U}_{\mathrm{s}}, \mathrm{km} / \mathrm{s}$ & $\mathrm{U}_{\mathrm{p}}, \mathrm{km} / \mathrm{s}$ & $\mathrm{P}, \mathrm{GPa}$ & $\mathrm{p}, \mathrm{g} / \mathrm{cm}^{3}$ & $\mathrm{~V}, \mathrm{~cm}^{3} / \mathrm{g}$ \\
\hline $\mathrm{Cu}$ & 0.25 & 6.03 & 0.35 & 5.87 & 2.95 & 0.339 \\
\hline $\mathrm{Cu}$ & 0.52 & 6.60 & 0.71 & 13.03 & 3.115 & 0.321 \\
\hline $\mathrm{Al}$ & 0.91 & 6.73 & 0.89 & 16.65 & 3.204 & 0.321 \\
\hline $\mathrm{Al}$ & 1.13 & 6.94 & 1.12 & 21.61 & 3.315 & 0.302 \\
\hline $\mathrm{Al}$ & 1.465 & 7.49 & 1.43 & 29.78 & 3.436 & 0.291 \\
\hline $\mathrm{Al}$ & 1.70 & 7.70 & 1.67 & 35.75 & 3.55 & 0.282 \\
\hline $\mathrm{Al}$ & 2.09 & 8.44 & 2.04 & 47.86 & 3.666 & 0.273 \\
\hline $\mathrm{Al}$ & 2.70 & 9.12 & 2.65 & 67.19 & 3.919 & 0.255 \\
\hline
\end{tabular}




\section{DYNAMIC ULTIMATE YIELD}

To obtain the information on dynamic strain at strain rate $\dot{\varepsilon}=10^{3}-10^{4} 1 / \mathrm{s}$, a direct Taylor method was used [7]. The experimental set for Taylor method [1] includes an acceleration unit for cylindrical samples and measurement equipment. The diameter of a runaway barrel is $20 \mathrm{~mm}$ at $1200 \mathrm{~mm}$ length. A barrier-30XGSA steel plate hardened to $\mathrm{RH}=40$ - was placed at $\sim 200 \mathrm{~mm}$ from the barrel cut. Electromagnetic ganges were used to measure the velocity of a shell-sample in each test at the barrel output. The velocity measurement error - $\pm 5 \%$. Figure 10 gives general views of composite samples before and after the impact. Initial diameter of the shell-sample $-20 \mathrm{~mm}$, initial length $-100 \mathrm{~mm}$. Table 6 gives the collision velocities $W_{0}$, finite length $L_{k}$; dynamic ultimate yield $\sigma_{f}^{\prime}$ derived classical Taylor formula $\sigma_{T}^{\prime}=-\rho_{0} W_{0}{ }^{2} / 2 \ln \left(L_{k} / L_{0}\right)$ as well as $\sigma_{T}^{n}$ value derived from mathematically treated data.

Table 6.

\begin{tabular}{|c|c|c|c|}
\hline $\mathrm{W}_{0}, \mathrm{~m} / \mathrm{s}$ & $\mathrm{L}_{\mathrm{k}}, \mathrm{mm}$ & $\sigma_{\mathrm{T}}^{\prime}, \mathrm{GPa}$ & $\sigma_{\mathrm{T}}^{\prime \prime}, \mathrm{GPa}$ \\
\hline 110 & 97 & 0.55 & \multirow{2}{*}{0.4} \\
\hline 155 & 94 & 0.54 & \\
\hline 170 & 93 & 0.55 & \\
\hline
\end{tabular}

In fig. 10 it is evident that in the sample tested at $W_{0}=170 \mathrm{~m} / \mathrm{s}$ the cracks came up. At higher velocities the sample was destructed.

Numerical modeling of a strained sample at its deceleration was done in the elastic - plastic approximation. The system of equations was formulated in Lagrange variables. Ball constituents of stress and strain ganges were coupled via Mi-Gruneizer equation of state. For each test result will a research approximation, constant value $\sigma_{\mathrm{T}}$ was found at which a calculated finite length of shell-sample $L_{k}$ and its shape coincide well with their test values. Finally, it was found that the test results are well described by constant $\sigma_{\mathrm{T}}=0.4 \mathrm{GPa}$. Figure 11 shown the calculation results. The calculations done with classic Taylor formula give higher values than the numerical modeling results for value $\sigma_{\mathrm{T}}$. 


\section{SHEAR STRENGTH}

The resistance of aluminium composite to plastic deformation or shear strength along side with compressibility, viscosity and elastisity, is one of the basic reological properties of a solid body which are needed to describe its behaviour under high-rate strain, including shock waves (SW).

The shear strength characterized by dynamic ultimate yield $Y_{8}$ under SW compression was studied by measurements of main stresses $\sigma_{x}$ (longitudinal) and $\sigma_{y}$ (transversal) which are described in detail in ref. [1]. From the viewpoint of elastic-plastic model $Y_{g}=\sigma_{x}-\sigma_{y}=2 \tau$ at $\sigma_{x}>\sigma_{\mathrm{HE}}$, where $\sigma_{\mathrm{HE}}$-amplitude of Hugonio elastic limit, $\tau$-shear stress.

By the established considerations with a 1-D deformation of elastic-plastic body in the plane shock wave:

$$
\begin{gathered}
\sigma_{x}=\sigma_{0}+2 / 3 Y_{z} ; \quad \sigma_{y}=\sigma_{0}-1 / 3 Y_{B} ; \\
\sigma_{0}=\left(\sigma_{x}+2 \sigma_{y}\right) / 3 ; \quad Y_{z}=(1-v / 1-2 v) \sigma_{\mathrm{HE}} \quad \text { at } \sigma_{x}=\sigma_{\mathrm{HE}}
\end{gathered}
$$

where $\sigma_{0}-\mathrm{a}$ ball constituent of the stress dyadic.

In the range of shock compression stresses from $2.3 \mathrm{GPa}$ to $22 \mathrm{GPa}, 15$ tests were accomplished with 9 types of explosive contact devices of known SW parameters in the shields. Figures 12.14 present several oscillograms of recorded main stress profiles $\sigma_{x}$ and $\sigma_{y}$ in the aluminium composite samples.

The experiment results are summed up in table 7 where in order the following is presented: studied material, explosive loading device shield material, mass velocity $U_{3}$ in the shield, measured velocities $\sigma_{x}, \sigma_{y}$, calculated average stress $\sigma_{0}$, dynamic ultimate yield $Y_{z}=\sigma_{x}-\sigma_{y}$ and ratio $\sigma_{0} / \sigma_{x}$ characterizing non-hydrostaticity of the stressed state of the aluminium composite behind plane SW front.

The study results have shown that the dynamic ultimate yield $Y_{g}$ as the main stress difference, characterizing the shear strength of a shock compressed material and determining the shock adiabat deviation from the quasi hydrostatic compression, is almost constant and equals $Y_{8}=0.24 \mathrm{GPa}$ for the aluminium composite in the studied range of shock compression stresses $\sigma_{x}$ from 2.3GPa to $22 \mathrm{GPa}$. High anisotropy of the stressed state behind SW front in the aluminium composite in the range of low stresses $\left(\sigma_{0} / \sigma_{\mathrm{x}}=0.9\right.$ at $\left.\sigma_{\mathrm{x}}=2.35 \mathrm{GPa}\right)$ decreases rather quickly with $\sigma_{x}$ growth (even at $\sigma_{x}=11.5 \mathrm{GPa} \sigma_{0} / \sigma_{x}=0.99$ ).

The measured test values for longitudinal stress $\sigma_{\mathrm{x}}$ within the measurement error $( \pm 8 \%)$ coincide with $\sigma_{x}$ values calculated in the solution of the problem on arbitrary rupture decay with the account of the obtained shock adiabat (see 
section 5) and the known parameters of shock waves in the shields. Values of $U$, and $U_{p}$ obtained with manganine gauges are given also in table 7 and fig. 9. 
Table 7.

Resultant measured main stress in aluminium composite

\begin{tabular}{|c|c|c|c|c|c|c|c|c|c|c|}
\hline $\bar{N}$ & \multicolumn{2}{|c|}{$\begin{array}{l}\text { Loading } \\
\text { device }\end{array}$} & \multicolumn{4}{|c|}{ Stresses, GPa } & \multirow[t]{2}{*}{$\sigma_{0} / \sigma_{x}$} & \multirow{2}{*}{$\begin{array}{c}\mathrm{U}_{\mathrm{s}}, \\
\mathrm{km} / \mathrm{s}\end{array}$} & \multirow{2}{*}{$\begin{array}{c}\mathrm{U}_{\mathrm{v}}, \\
\mathrm{km} / \mathrm{s}\end{array}$} & \multirow[t]{2}{*}{ Notes } \\
\hline & $\begin{array}{c}\text { Shield } \\
\text { material }\end{array}$ & $\begin{array}{c}\mathbf{U}_{\mathbf{3}} \\
\mathbf{k m} / \mathbf{s}\end{array}$ & $\sigma_{x} \pm 8 \%$ & $\overline{\sigma_{\mathrm{v}} \pm 8 \%}$ & $\overline{\sigma_{0}}$ & $Y_{g}=2 \tau$ & & & & \\
\hline $\begin{array}{l}1 \\
2\end{array}$ & $\begin{array}{c}\text { Copper } \\
\text { M1 }\end{array}$ & 0,098 & $\begin{array}{l}2,3 \\
2,4\end{array}$ & $\begin{array}{l}2,0 \\
2,0\end{array}$ & $\begin{array}{l}2,10 \\
2,13\end{array}$ & $\begin{array}{l}0,3 \\
0,4\end{array}$ & $\begin{array}{l}0,91 \\
0,89\end{array}$ & 6,28 & 0,135 & \\
\hline $\begin{array}{l}3 \\
4\end{array}$ & $\begin{array}{c}\text { Copper } \\
\text { M1 }\end{array}$ & 0,175 & $\begin{array}{l}3,6 \\
3,6\end{array}$ & $\begin{array}{l}3,4 \\
3,3\end{array}$ & $\begin{array}{l}3,47 \\
3,40\end{array}$ & $\begin{array}{l}0,2 \\
0,3\end{array}$ & $\begin{array}{l}0,96 \\
0,94\end{array}$ & 5,65 & 0,23 & \\
\hline $\begin{array}{l}5 \\
6\end{array}$ & $\begin{array}{c}\text { Copper } \\
\text { MI }\end{array}$ & 0,18 & $\begin{array}{l}3,9 \\
3,8\end{array}$ & $\begin{array}{l}3,7 \\
3.6\end{array}$ & $\begin{array}{l}3,77 \\
3,67\end{array}$ & $\begin{array}{l}0,2 \\
0.2\end{array}$ & $\begin{array}{l}0,96 \\
0,96\end{array}$ & 5,75 & 0,24 & \\
\hline $\begin{array}{l}7 \\
8 \\
\end{array}$ & $\begin{array}{c}\text { Copper } \\
\text { M1 }\end{array}$ & 0,22 & $\begin{array}{l}5,1 \\
4,9 \\
\end{array}$ & $\begin{array}{l}4,8 \\
4,7 \\
\end{array}$ & $\begin{array}{l}4,90 \\
4,77 \\
\end{array}$ & $\begin{array}{l}0,3 \\
0,2 \\
\end{array}$ & $\begin{array}{l}0,96 \\
0,97 \\
\end{array}$ & 5,92 & 0,305 & \\
\hline $\begin{array}{c}9 \\
9 \\
10\end{array}$ & $\begin{array}{l}\text { Copper } \\
\text { M1 }\end{array}$ & $\begin{array}{l}0,35 \\
0,35\end{array}$ & $\begin{array}{l}8,5 \\
8,6\end{array}$ & 8,3 & 8,37 & 0,2 & 0,98 & $\overline{6,39}$ & 0,48 & gange break \\
\hline $\begin{array}{l}11 \\
12 \\
\end{array}$ & $\begin{array}{c}\text { Copper } \\
\text { M1 }\end{array}$ & $\begin{array}{l}0,47 \\
0,52\end{array}$ & $\begin{array}{l}11,5 \\
13,0 \\
\end{array}$ & $\begin{array}{l}11,3 \\
12.8 \\
\end{array}$ & $\begin{array}{l}11,37 \\
12,87 \\
\end{array}$ & $\begin{array}{l}0,2 \\
0,2 \\
\end{array}$ & $\begin{array}{l}0,99 \\
0,99 \\
\end{array}$ & $\begin{array}{l}6,43 \\
6,66 \\
\end{array}$ & $\begin{array}{l}0,645 \\
0,705 \\
\end{array}$ & \\
\hline $\begin{array}{l}13 \\
14\end{array}$ & $\begin{array}{c}\text { Aluminium } \\
\text { AD1 }\end{array}$ & 0,91 & 16,9 & $\sim 16,6$ & 16,70 & $-0,3$ & 0,99 & 6,89 & 0,895 & \\
\hline $\begin{array}{l}15 \\
16\end{array}$ & $\begin{array}{c}\text { Aluminium } \\
\text { AD1 }\end{array}$ & 1,15 & 21,8 & $\sim 21,6$ & 21,66 & $\sim 0,2$ & 0,99 & 6,90 & 1,140 & \\
\hline
\end{tabular}




\section{SPALL STRENGTH}

\subsection{Plate IMPACT}

To do the study of the spallation strength by continuous recording of sample free surface motion with a capacitive velocity gange, facility BUT-76 [9] was used which is based on a ballistic shock tube for projectile runaway with a measuring set (fig.15). The recorded "history" of current velocity of the free surface holds the information on the spallation kinetics. The studied sample (4) $50 \mathrm{~mm}$ in diameter and $5-10 \mathrm{~mm}$ thick was place in the aluminium cartridge which was mounted at the $76.2 \mathrm{~mm}$ caliber and $10.8 \mathrm{~mm}$ long barrel headpiece end. Shell (5) of 0.2-0.8kg mass with on impactor of aluminium or aluminium composite 2.5-5mm thick is accelerated in the evacuated barrel by the compressed air energy. With the plane collision of the impactor (3) with the sample (4), slant angle does not exceed $0.5^{*} 10^{-3} \mathrm{rad}$ at $50 \mathrm{~mm}$ diameter. The barrel headpiece (1) is coupled with the braking chamber (2) which facilitates soft deceleration of the loaded sample and preserves it for the further metallographic analysis. The facility is equipped with the measuring set which measures the flying up velocity $W$ of the impactor and free surface velocity profile $W(t)$ of the studied sample. The velocity profile was measured with a capacitive gange at $\pm 10 \%$ accuracy. The impactor flying-up velocity is measured with electrocontacts at higher accuracy $\pm 0.5 \%$ that allows to accomplish reliable norming of $W(t)$ function. The sizes of impactor $\left(\Delta_{e x}\right)$ - target $\left(\Delta_{m}\right)$ pairs were chosen to provide for uniform strain and constituted 2.5-5.0 and 5.0-10.0 mm. For each noted impactor - target pair 5-6 tests were conducted in which impactor velocity was measured to implement the following loading conditions for the samples in the target which are controlled with metallographic analysis (see subsection 8.4). A - no destruction nuclei observed in 200 time magnified microsections of sample longitudinal sections; B separate nuclei of destruction in the form of micropores appeared in the spallation plane; C - coalescence of separate destruction nuclei in a main crack; D complete sample destruction in pieces. In each test with the capacitive gange with the protective ring the continuous reconding of sample face surface velocity $W(t)$ was done (Figs. 16,17). The information obtained in the tests was used to define several characteristics of the sample material with the following relationships:

$$
\begin{gathered}
\sigma_{p}=0.5 \rho_{0} \mathrm{C}_{0}(\Delta W+\delta \mathrm{W}) \\
\sigma_{0}=0.5 \rho_{0} \mathrm{C}_{0} \mathrm{~W}_{0} ; \quad \sigma_{\mathrm{FE}}=0.5 \rho_{0} \mathrm{C}_{1} \mathrm{~W}_{\mathrm{d}} \\
\dot{\varepsilon}=1 / 2(\partial \mathrm{W} / \partial t)\left(1 / \mathrm{C}_{0}\right) ; \\
\delta \mathrm{W}=1 / 2 \frac{\partial \mathrm{W}}{\partial t}\left(\frac{\delta}{\mathrm{C}_{0}}-\frac{\delta}{\mathrm{C}}\right) \\
\lambda=\left(\sigma_{0}^{2} * \delta\right) / \mathrm{E} \frac{(1+v)(1-2 v)}{(1-v)}
\end{gathered}
$$


where $\rho_{0}=2.77 \mathrm{~g} / \mathrm{cm}^{3} ; \quad C_{0}=5.68 \mathrm{~km} / \mathrm{s} ; \quad C_{1}=7.16 \mathrm{~km} / \mathrm{s} ; \quad E=102.6 \mathrm{GPa} ;$ $v=0.308$ - material constants; $\Delta W=W_{2}-W_{1}$ - difference in the velocities in the first maximum $-W_{1}$ and first minimum of $W(t)$ function, $\partial W / \partial t-W(t)$ graph slope in front of $\mathrm{W}_{2} ; \mathrm{W}_{\mathrm{d}}$ - elastic precursor amplitude; $\sigma_{0}, \sigma_{p}, \sigma_{\mathrm{HE}}-$ pressure in the shock wave, tensile stress and Hugonio ultimate yield; $\dot{\varepsilon}-$ strain rate of the material in the spallation area; $\lambda$ - specific material tearing per surface area unit (destruction energy); $\delta$ - tearing thickness; $T$ - duration of compression wave oscillation in the spallation layer. Table 8 presents this information quantitatively.

The analysis of obtained results testifies for the fact that under the rectangular stress pulse of $\sim 0.7-1.5 \mathrm{~ms}$ and $\sigma_{0}=1-2 \mathrm{GPa}$ the samples are destructed at $\sigma_{p}=0.52-0.65 \mathrm{GPa}$ and $\dot{\varepsilon}=\left(8.8^{*} 10^{3}-1.4^{*} 10^{4}\right) \mathrm{s}^{-1}$ or $\lambda=3-6 \mathrm{~J} / \mathrm{cm}^{2}$. The sample destruction is nucleated in the form of micropores and microcracks both in aluminium and in incorporated filler that explains a somewhat lower strength of ceramic material compared to the metal aluminium. Providing the destruction of large-scale samples occur at although lower impactor velocities but at higher stored elastic energy in it. The width of material destruction zone in the larger samples $(\Delta=10 \mathrm{~mm})$ constitutes $\sim 1.1 \mathrm{~mm}$ and in smaller samples $(\Delta=5 \mathrm{~mm})$ $-0.4 \mathrm{~mm}$. That is, under the studied sample destruction an evident scale effect of the energy nature manifests itself.

In all tests a two-wave configuration of the shock wave was observed (see figs. 16,17). Elastic precursor amplitude is $\bar{W}_{d}=17 \mathrm{~m} / \mathrm{s}$ that corresponds to Hugonio ultimate yield $\sigma_{\mathbf{H E}}=0.17 \mathrm{GPa}$ 
Table 8

Results of Spall Strength Study at Plate Impact

\begin{tabular}{|c|c|c|c|c|c|c|c|c|c|c|c|c|c|}
\hline $\begin{array}{c}\Delta \mathrm{ex}_{-} \\
\Delta \mathrm{m} \\
\mathrm{mm}- \\
\mathrm{mm}\end{array}$ & $\begin{array}{l}\mathbf{W}_{\mathbf{0}} \\
\mathrm{m} / \mathrm{s}\end{array}$ & $\begin{array}{l}\mathrm{W}_{1} \\
\mathrm{~m} / \mathrm{s}\end{array}$ & $\begin{array}{l}W_{2} \\
m / s\end{array}$ & $\begin{array}{l}\mathrm{W}_{\mathrm{et}} . \\
\mathrm{m} / \mathrm{s}\end{array}$ & $\begin{array}{c}(\partial W / \partial t) 10^{-} \\
6 \\
\mathrm{~m} / \mathrm{s}^{2}\end{array}$ & $\begin{array}{l}\sigma_{\mathrm{HE}} \\
\mathrm{GPa}\end{array}$ & $\begin{array}{r}\sigma_{0} \\
\mathrm{GPa}\end{array}$ & $\begin{array}{r}\sigma_{\mathfrak{p}} \\
\mathrm{GPa}\end{array}$ & $\begin{array}{c}\lambda \\
\mathrm{J} / \mathrm{sm}^{2}\end{array}$ & $\mathrm{~s}^{-1}$ & $\begin{array}{c}\mathrm{T} \\
\mathrm{ms}\end{array}$ & $\begin{array}{c}\mathrm{C}_{1} \\
\mathrm{~km} / \mathrm{s}\end{array}$ & $\begin{array}{c}\text { Degree } \\
\text { of } \\
\text { damage }\end{array}$ \\
\hline \multirow{4}{*}{$5-10$} & 123,1 & 104.5 & - & 10 & - & 0.10 & 0.97 & - & 3.3 & - & - & - & $\overline{\mathbf{A}}$ \\
\hline & 166.9 & 130.8 & 54.9 & 10 & 105 & 0.10 & 1.32 & 0.60 & 6.1 & $9.210^{3}$ & 1.65 & 7.2 & C \\
\hline & 172.9 & 148.0 & 77 & 17 & 100 & 0.17 & 1.36 & 0.65 & 6.4 & $8.810^{3}$ & 1.70 & 77.1 & $\mathrm{C}$ \\
\hline & 207.0 & 200 & 130 & 17 & 105 & 0.17 & 1.63 & 0.64 & 9.2 & $9.210^{3}$ & 1.70 & 7.1 & $\bar{D}$ \\
\hline \multirow{6}{*}{$2.5-5$} & 156.7 & 129.9 & - & 10 & - & 0.10 & 1.24 & - & 2.7 & - & 1.50 & 6.7 & $\bar{A}$ \\
\hline & 163.2 & 133.5 & - & 21 & - & 0.21 & 1.29 & - & 2.9 & - & 1.45 & 6.9 & A \\
\hline & 173.9 & 153 & 94.3 & 16 & 160 & 0.16 & 1.37 & 0.53 & 3.3 & $1.410^{4}$ & 0.86 & 7,0 & $\bar{B}$ \\
\hline & 193.2 & 167 & 102 & 13 & 150 & 0.13 & 1.52 & 0.58 & 4.01 & $1.210^{4}$ & 0.85 & 7.1 & B \\
\hline & 208 & 180.7 & 123.5 & 31 & 160 & 0.31 & 1.64 & 0.52 & 4.7 & $1.410^{4}$ & 0.83 & 7.2 & C \\
\hline & 238.6 & 224.8 & 155.4 & 24 & 160 & 0.24 & 1.85 & 0.62 & 6.1 & $1.410^{4}$ & 0.81 & 7.3 & D \\
\hline
\end{tabular}




\subsection{EXPLOSIVE LOADING}

The experiments on spall strength measurements in non-stationary SW with the records of time function of stress $\sigma(t)$ at the interface "studied samplePMMA" are shown in fig.18. The studied sample (3) in the disc form $10 \mathrm{~mm}$ thick and $50 \mathrm{~mm}$ in diameter which was pressed in the aluminium cartridge, was loaded in the contact explosion of plastic $\mathrm{HE}$ charge (2) of $\sigma_{\mathrm{HE}}=10,15$ and $20 \mathrm{~mm}$ thickness which has density $\rho_{\mathrm{KE}}=1.51 \mathrm{~g} / \mathrm{cm}^{3}$ and detonation velocity $D_{\text {HE }}=7.8 \mathrm{~km} / \mathrm{s}[10]$. HE was initiated by the impact of $0.4-0.5 \mathrm{~mm}$ thick aluminium foil of the plane detonation wave generator (1). The foil velocity at the moment of the impact against HE was $\sim 2.8 \mathrm{~km} / \mathrm{s}$. In this case the difference in time for the detonation wave front over the surface limited by $57 \mathrm{~mm}$ diameter, did not exceed $0.13 \mathrm{~ms}$ (see fig.19).

The stress profile $\sigma(t)$ at the sample-PMMA interface (5) was measured by a wire manganine gauge, the stress was calculated with the formula [1]:

$$
\sigma=\left[34.5 \Delta R / R+7.5(\Delta R / R)^{2}\right], G p a
$$

In ref.[1] the calculation technique for $\sigma_{p}$ in $\sigma-U_{p}$ coordinates according to the experimental values of $\sigma_{1}$ and $\sigma_{2}$ stresses is presented [11]. For the graphs, the shock adiabats were used in the form of linear $U_{s}-U_{p}$ relationship for the studied sample:

$$
\mathrm{U}_{\mathrm{s}}=5.54+1.356 \mathrm{U}_{\mathrm{p}} \mathrm{km} / \mathrm{s}\left(\rho_{0}=2.77 \mathrm{~g} / \mathrm{cm}^{3}\right) \text { (current work) }
$$

and PMMA [12]:

$$
\mathrm{U}_{\mathrm{s}}=2.59+1.51 \mathrm{U}_{\mathrm{p}} \mathrm{km} / \mathrm{s}\left(\rho_{0}=1.18 \mathrm{~g} / \mathrm{cm}^{3}\right)
$$

Table 9 sums up the experimental results, where $\sigma_{0}$-maximal calculated stress in the sample at the interface with explosion products which was defined according to ref.[13]; $\sigma_{1}^{*}-\mathrm{SW}$ amplitude in the sample at $10 \mathrm{~mm}$ depth (measured in individual tests when PMMA was substituted for $10 \mathrm{~mm}$ thick sample).

Figure 20 presents $\sigma(t)$ oscillogram of $S W$ in the sample at $10 \mathrm{~mm}$ depth at $\delta_{\text {HE }}=10 \mathrm{~mm}$. Figure 21 gives $\sigma(t)$ oscillogram at the sample PMMA interface at $\delta_{\mathrm{HE}}=10 \mathrm{~mm}$, characteristic points $\sigma_{1}$ and $\sigma_{2}$ are noted which were needed for $\sigma_{p}$ calculation.

The comparison of table 8 and 9 results testifies for the fact that the increased intensity of the sample loading by more than an order does not result in the increased stress of aluminium composite stress $\left(\sigma_{p}=0.52-0.65 \mathrm{GPa}\right.$ at low intensity loading with the plate impact and $\sigma_{p}=0.57-0.80 \mathrm{GPa}$ under explosive 
loading), and the spall strength of the aluminium composite car be characterised by $\sigma_{p}=0.62 \mathrm{GPa}$.

Results of Shall Stregth Study under

Table 9.

Explosive loading

\begin{tabular}{|c|c|c|c|c|c|c|}
\hline \multirow{2}{*}{$\begin{array}{c}\text { HE } \\
\text { charge } \\
\text { thickness } \\
\text { mm }\end{array}$} & \multirow{2}{*}{$\begin{array}{c}\text { Sample } \\
\text { thickness } \\
\text { mm }\end{array}$} & \multicolumn{4}{|c|}{ Stress $\mathbf{G P a}$} & \multirow{2}{*}{$\sigma_{p}$} \\
\hline & & $\sigma_{0}^{*}$ & $\sigma_{1}^{*}$ & $\sigma_{1}$ & $\sigma_{2}$ & \\
\hline 10 & 10 & 29.5 & 16.8 & 7.11 & 3.22 & 0.66 \\
\hline 15 & 10 & 29.5 & 21.0 & 9.00 & 3.82 & 0.57 \\
\hline 20 & 10 & 29.5 & & 9.72 & 3.83 & 0.80 \\
\hline
\end{tabular}

\subsection{TEMPERATURE EFFECT}

The study of the temperature effect on the ahuminium composite spallation was conducted with calculation-experimental method [1] and microstructure

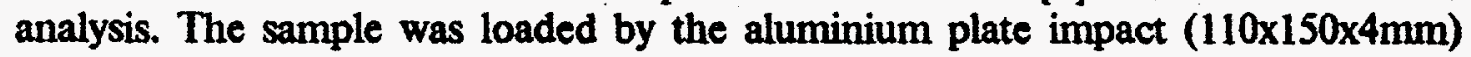
accelerated by plastic HE explosion products $\left(\rho_{0}=1.51 \mathrm{~g} / \mathrm{cm}^{3}, D_{\mathrm{FE}}=7.8[10]\right)$. The impactor velocity was varied by changing the HE layer thickness. The tests were done both with and without sample heating to $+560^{\circ}$ temperature. Table 11 show the results of the study.

\subsection{METALLOGRAPHIC STUDY}

The degree and character of spallation as well as probable structural changes in the aluminium composite were studied with 3 types of thermally treated samples (see fig.22a,b,c). After shock-wave loading with heating and without heating. According to the observed destruction pattern, the degree of the material spallation is arbitrary divided in $\mathbf{4}$ stages:

D - complete spallation - separation of the whole spall layer;

B - intense microdestruction - substantial destruction available in the zone of spallation in the form of isolated or clustered cracks or pores;

C - slight microdestruction - small amount of isolated cracks or pores available in the spallation zone;

D - actually, no spallation.

Tables 10-11 give the data on the degree of spallation destruction of the studied samples, and figs. 23-26 show the character of their spallation.

As it is evident from the obtained results, the sample spall (fig. 22a, b) without heating is formed in the clustering of individual wide cracks or voids (figs.23b, 24b). The spall zone in the samples $5 \mathrm{~mm}$ thick is formed at $\sim 3 \mathrm{~mm}$ from the loaded surface, and in $10 \mathrm{~mm}$ thick samples - at $\sim 7 \mathrm{~mm}$ from the loading surface. The spall in the conical samples (fig.22c) without heating is also formed as a result of individual wide cracks or voids clustering (fig. $25 \mathrm{~g}$ ), the spall zone is formed at $\sim 7-8 \mathrm{~mm}$ from the loaded surface (fig. $25 \mathrm{~b}, \mathrm{c}$ ); with the increased load 
to $W_{0}=460 \mathrm{~m} / \mathrm{s}$, except the partial spallation destruction the spall crossing the whole sample in thickness (fig. $25 \mathrm{c}$ ) is also formed. In the conical samples with $560^{\circ} \mathrm{C}$ heating the spall is formed as a result of uniting of several individual pores (fig.26g) and is a zone $\sim 3 \mathrm{~mm}$ wide at $\sim 2 \mathrm{~mm}$ from the loaded surface (fig.26b).

\section{Results of Metallographic Study of Sample Destruction}

Table 10

\begin{tabular}{|c|c|c|}
\hline N sample types & $\mathrm{W}_{0} \mathrm{~m} / \mathrm{s}$ & Degree of spallation destruction \\
\hline 1a & 112.0 & actually no spallation destruction \\
\hline $2 a$ & 145.5 & $-{ }^{-\kappa}-$ \\
\hline $3 \mathbf{a}$ & 156.7 & $-{ }_{-\alpha}-$ \\
\hline$\overline{4 a}$ & 163.2 & $-"$ \\
\hline $5 \mathbf{a}$ & 173.9 & $-{ }^{-\prime}-$ \\
\hline $6 \mathbf{a}$ & 193.2 & - - \\
\hline $7 \mathbf{a}$ & 208 & intense microdestruction \\
\hline$\overline{8 b}$ & 114.8 & actually no spallation destruction \\
\hline $9 \mathrm{~b}$ & 123.1 & - \\
\hline $10 b$ & 172.9 & slight microdestruction \\
\hline $11 \mathrm{~b}$ & 166.9 & $-{ }_{-6}$ \\
\hline
\end{tabular}

Table 11

Results of Metallographic Study of Sample Destruction in Temperature Effect Research

\begin{tabular}{|c|c|c|c|}
\hline $\begin{array}{c}\text { N sample } \\
\text { type }\end{array}$ & $\mathrm{t}^{0} \mathrm{C}$ & $\mathrm{W}_{0} \mathrm{~m} / \mathrm{s}$ & Degree of spallation destruction \\
\hline lc & $\begin{array}{c}\text { without } \\
\text { heating }\end{array}$ & 190 & actually no spallation destruction \\
\hline $2 \mathrm{c}$ & $-{ }^{-6}-$ & 240 & slight microdestruction \\
\hline $3 \mathrm{c}$ & $-{ }^{-6}-$ & 460 & $\begin{array}{c}\text { partial spallation destruction and } \\
\text { complete destruction in the form of a } \\
\text { spall }\end{array}$ \\
\hline $4 \mathrm{c}$ & 560 & 100 & actually no spallation destruction \\
\hline $5 \mathrm{c}$ & 560 & 120 & slight microdestruction \\
\hline
\end{tabular}




\section{CONCLUSIONS}

In the course of stage 3.2 of task 003 of subcontract $0002 \mathrm{P}$ 0004-95 between RFNC - VNIIEF and LANL (USA) on the study of aluminium composite under VNIIEF dynamic loads:

- test samples of 10 dimension types were fabricated;

- composite micro- and macrostructure, microhardness were studied; nonuniform SiC particle distribution in the aluminium basis was revealed;

- elastic velocities $\left(C_{L}=7.16 \mathrm{~km} / \mathrm{s}, C_{t}=3.77 \mathrm{~km} / \mathrm{s}\right)$, elastic moduli $(\mathrm{E}=102.6 \mathrm{GPa}, \mathrm{K}=89.2 \mathrm{GPa}, \mathrm{G}=39.2 \mathrm{GPa}, v=0.308$ ) were identified;

- tension diagrams were determined at $\mathrm{T}=25^{\circ} \mathrm{C}$ and strain rates $\dot{\varepsilon}=(200$ $260) \mathrm{s}^{-1}$ as well as the compression diagrams at $\mathrm{T}=-50,25,100,300^{\circ} \mathrm{C}$ and relative $\dot{\varepsilon}=(200-500) \mathrm{s}^{-1}$;

- crack resistance was identified at $T=-50,25,100,300^{\circ} \mathrm{C}$; at relative impact velocities $(0.63-1.4)^{*} 10^{4} \mathrm{~s}^{-1}$, a wean crack resistance of the composite is noted;

- dynamic deformation at $\dot{\varepsilon} \approx 10^{3}-10^{4} \mathrm{~s}^{-1}$ is described by the elastic-plastic model of constant ultimate yield $\sigma_{\tau}=0.4 \mathrm{GPa}$;

- dynamic ultimate yield function was studied as a difference in the main stresses under shock wave compression. In 2.3-2.2GPa stress range the ultimate dynamic yield $\mathrm{Yg}_{\mathrm{g}}$ is almost constant and constitutes $0.24 \mathrm{GPa}$;

- it was found that the magnitude of the spallation strength for the aluminium composite is almost constant $\sigma_{p}=0.62 \mathrm{GPa}$ in $1-2 \mathrm{GPa}$ to $29 \mathrm{GPa}$ stress range;

- detailed metallographic study was accomplished to learn the degree of spallation destruction character in the loaded samples. 


\section{REFERENCES}

1. Report on contract 0002 P 0004-95 (Task 003). Study of destruction and resistance to plastic deformation for aluminium composite under dynamic loads. Methods. Novikov S.A., Bat' kov Yu.V., Polyakov L.V. et al. VNIIEF, 1995.

2. D.S.Hughes, W.I.Pondrom and R.L.Mims. Transmission of Elastic Pulses in Metal Rods. Phys., v.75, N10, 1949.

3. RD 50-344-82. Methodological instructions Identification of crack resistance characteristics under dynamic loading. M. Izd-vo standartov, 1983.

4. L.V.Al'tshuler. Shock wave application in high pressure physics. UFN, 85(2), 1965, p. 197.

5. L.V.Al'tshuler, A.A.Bakanova, I.P.Dugoladov, E.A.Dynin, R.F.Trunin, B.S.Chekin. Shock adiabats of metals. New data, statistical analysis and universal laws. PMTF, N2, 1981, p.3.

6. Properties of condensed substances under high pressures and temperatures. Collection of articles edited by R.F.Trunin. Minatom, CNII upravleniya, ekonomiki i informatzii, 1992.

7. Jones S., Gills P., Foster J. On the equation of mation of the underformed section of a Taylor impact // J. Appl. Phys. - 1987-61. N2-p.499502.

8. Novikov S.A., Petrov V.A. Explosive facilities for mechanical tests of materials and constructions (Review). M. CNIIAtominform, 1983, p.37.

9. V.N.Mineev, V.P.Pogorelov, A.G.Ivanov et al. Facilities for composite material and construction behaviour study under dynamic loading. FGV, 1978, N3.

10. S.A.Novikov. Strength under quasistatic and shock wave loading. FGV, 1985, N6, p.77-85.

11. Yu.V.Bat'kov, A.B.Glushak, S.A.Novikov. Manganine gange applications for spallation phenomena study in metals under explosive loading. In book: All-Union meeting on detonation. Presentations. 1988, v.1, p.154-157.

12. Yu.V.Bat'kov, V.K.Golubev, S.A.Novikov et al. On spallation destruction recording in copper and lead under explosive loading. FGV., 1988, Ni, p.89-92.

13. S.A.Kinelovskii, Yu.A.Trishin. On the decomposition calculation at interface HE-condensed matter. FGV, 1984, N1, p.126-133. 


\author{
RFNC - VNIIEF \\ LosAlamos National Laboratory
}

Material Behaviour Study under Quasistatic Loading

(3 stage of task 003 of contract 0002P0004-95)

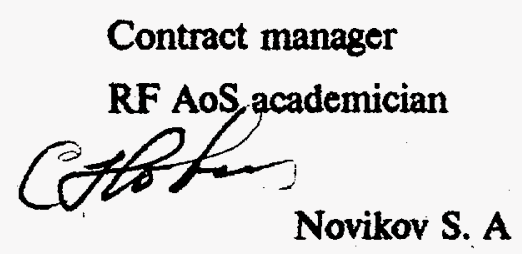

Principal Investigator

Polyakov L. V. 


\begin{abstract}
According to the requirement of 3.4 stage of task 003 subcontract 0002P0004-95 betireen RNFC-VNIIEF and LANL (LosAlamos National Laboratory), the research of aluminium composite of $20 \%$ weight $\mathrm{SiC}$ was conducted under quasistatic loading $\left(\varepsilon=\left(10^{-4}-10^{-3}\right) \mathrm{s}^{-1}\right.$

In $(-70-300){ }^{0} \mathrm{C}$ temperature rarge the values of mechanical properties $\sigma_{b}, \sigma_{0,2}, \delta$ and $\psi$ were identified as well as elastic characteristics $E$ and $v$; strain diagrams $\sigma-\varepsilon$ were built.

The experiments done to obtain $\sigma(\varepsilon)$ funitions at temperatures $(400-500)^{0} \mathrm{C}$ with $\sigma$ and $\delta$ characteristic identification.
\end{abstract}




\section{Contents}

Introduction

1.Experiment arrangement

5

2.Research results

3.Conclusion

7

4.References

8 


\section{Introduction}

The study of mechanical properties of the aluminium composite at different temperatures ( from $-70^{\circ} \mathrm{C}$ to $+300^{\circ} \mathrm{C}$ ) under qnisistatic $\left(10^{-4} 0^{-3}\right) \mathrm{s}^{-1}$ loading is the stage of works for contract 0002P0004-95. The previous report [1] gires the techniqnes for material experimental research. 


\section{Experiment arrangement}

The aluminium composite properties were studied with samples after thermal treatment :

1) .regime $\mathrm{T} 6$ : exposure -8 hours at $\mathrm{T}=530^{\circ} \mathrm{C}$ with water cooling lat $\mathrm{T}=65-70^{\circ} \mathrm{C}$. 2).aging at $\mathrm{T}=154^{\circ} \mathrm{C}$ for 5 hours with air cooling.

The samples were cut out of the blank across (1) and along (2) the axis.

The test samples are presented in fig. 1.

Type 1 samples were used to identify the elastic characteristies of the matirial, E and $v$ The longitudinal and transversal strains were measured with tensoresistors KF5P1 and digital tensometric bridge CTM-3 at 10 o.e.g. measurement accuracy. The tensoresistors were glued on the sample in longitudinal ( 2 pieces) and transversal ( 1 piece ) direction

Characterictics $\mathrm{E}$ and $v$ were identified to $\mathrm{T}=200^{\circ} \mathrm{C}$ (the operation limit for the tensoresistors ).

Type 2 samples were used to define mechenical characteristics $\sigma_{b}, \sigma_{0,2}, \delta$ and $\psi$ and to obtain $\sigma-\varepsilon$ diagrams. To record " force-absolute extention " diagram, the sample strain was measured with $2 \mathrm{Smm}$ base extensor. The tests were accomplished at traverse velocity of $V=1,67 * 10 \mathrm{~m} / \mathrm{s}$. The properties were studied in $-70^{\circ} \mathrm{C}$ to $300^{\circ} \mathrm{C}$ temperature range

Type 3 sample were used in the experiments on material behaviour at $400{ }^{\circ} \mathrm{C}$ and $500^{\circ} \mathrm{C}$ temperatures. With them characteristics $\sigma_{\mathrm{b}}$ and $\delta$ were identified as well as function $\sigma(\varepsilon)$. At $500^{\circ} \mathrm{C}$ the test were done with three impact velocities.

In total 16 samples of type 1,25 samples of type 2 and 8 samples type 3 were tested. The samples were exposed at specified temperature for $30-60 \mathrm{~min}$ (depending on the temperature). The exposure time was definedwith a control sample in the middle of which a thermopair was mounted.

The test were located at INSTRON 1185 facility. 


\section{Research Results.}

Table 1 and figure 2 (averaged results for 2-3 samples ) give the material mechanical characteristic dependent on temperature for two direction of sample cuttings. The statistics analysis of the obtained results was not accomplished becaus the amount of the tested samples is too small. Figure 3a gives typical functions $\sigma(\varepsilon)$ at different temperatures.

Tension diagrams for 20,100 and $200^{\circ} \mathrm{C}$ temperatures were built with " force sample extension " diagram data. For $-70^{\circ} \mathrm{C}$ and $+300^{\circ} \mathrm{C}$ temperatures they were obtained via recalculations of computer diagrams " force - traverse motion " with the technique isted in ref. [2].

\section{Mechanical characteristics.}

Table 1.

* - characteristics for the given temperature are presented according to sample 1 . Table 2 presents the experiment results (by samples ) at $400^{\circ} \mathrm{C}$ and $500^{\circ} \mathrm{C}$ temperatures. Figure 3.b gives $\sigma(\varepsilon)$ functions at $400^{\circ} \mathrm{C}$ ( sample 2 ) and $500^{\circ} \mathrm{C}$ (samplse 3 ).

\section{Strength and Plasticity at high Temperatures.}

Table 2.

Analysing the experiment results we must mention their instability which is especially evident at high temperatures This is seen by the table 2 results for $500^{\circ} \mathrm{C}$ temperature.

Probably, this fact can be explained by insufficiently homogenious material structure with non-unifom distrifution of carbide phase that was revealed in metallographic reseach. 
Mechanical characteristics

\begin{tabular}{|c|c|c|c|c|c|c|c|}
\hline \multirow{2}{*}{\begin{tabular}{|l|} 
sample \\
cutting \\
direction
\end{tabular}} & $T$ & $\sigma_{b}$ & 60,2 & $\delta$ & $\psi$ & $E$ & \multirow{2}{*}{$\nu$} \\
\hline & ${ }^{\circ} \mathrm{C}$ & \multicolumn{2}{|c|}{$\mathrm{MPa}$} & \multicolumn{2}{|c|}{$\%$} & $\mathrm{GPa}$ & \\
\hline \multirow{7}{*}{ I } & -70 & - & - & - & - & 103.9 & 0.305 \\
\hline & -50 & - & - & - & - & 103.8 & 0.293 \\
\hline & 24 & 305 & 270 & 0.7 & 2.2 & 102.6 & 0.298 \\
\hline & 100 & 290 & 250 & - & - & 100.3 & 0.280 \\
\hline & 150 & 270 & 240 & 1.0 & 2.6 & - & - \\
\hline & $* 200$ & 255 & 240 & 1.2 & 2.5 & 95.0 & 0.305 \\
\hline & $* 290$ & 70 & 65 & 7.0 & 14 & - & - \\
\hline \multirow{6}{*}{ II } & -70 & 335 & 330 & 0.24 & 1.3 & 104.0 & 0.270 \\
\hline & -50 & 330 & 320 & 0.26 & 1.0 & 103.2 & 0.305 \\
\hline & 24 & 320 & 300 & 0.5 & 1.0 & 102.3 & 0.313 \\
\hline & 100 & 309 & 280 & 0.7 & 1.5 & 100.9 & 0.318 \\
\hline & 200 & 260 & 245 & 0.9 & 2.0 & 91.9 & 0.306 \\
\hline & 290 & 72 & 68 & 5.0 & 16.5 & - & - \\
\hline
\end{tabular}

* - characteristics for the given temperature are presented according to sample 1 .

Strength and Plasticity at high Temperatures

\begin{tabular}{|c|c|c|c|c|}
\hline $\mathrm{T}$ & $\dot{E}$ & $\mathrm{~N}$ & $\sigma b$ & $\delta$ \\
\hline \multirow{3}{*}{400} & $\mathrm{c}^{-1}$ & & $\mathrm{MPa}$ & $\%$ \\
\hline \multirow{3}{*}{500} & \multirow{3}{*}{$0.7 * 10^{-3}$} & 1 & 41 & 8.5 \\
\cline { 3 - 6 } & \multirow{2}{*}{$0.7 * 10^{-3}$} & 3 & 38 & 9.2 \\
\cline { 2 - 6 } & \multirow{2}{*}{$0.70^{-3}$} & 1 & 19 & 10. \\
\cline { 2 - 6 } & \multirow{2}{*}{$1.4 * 10^{-3}$} & 5 & 12 & 20. \\
\cline { 2 - 6 } & & 6 & 20 & 30. \\
\hline
\end{tabular}




\section{Conclusion}

We can note the following based on the aluminium composit study :

- sample cutting direction does not substantially affect material properties;

- elastic modulus magnitude increases negligibly with temperature increase to $200{ }^{\circ} \mathrm{C}$. Poisson's coefficient is practically always constant and constitutes 0.30 ;

- with temperature increase from $-70^{\circ} \mathrm{C}$ to $+200{ }^{\circ} \mathrm{C}$ a certain decrease in strength (10$20 \%$ ) and insignificant increase in plasticity are seen, the material is deformated uniformly; at $300^{\circ} \mathrm{C}$ an abrupt decrease in strength and plasticly growth occur deformation becomes localized; this process continues at $400{ }^{\circ} \mathrm{C}$ and $500{ }^{\circ} \mathrm{C}$ also, finally ultimate strength value drops from $320 \mathrm{MPa}$ at room temperature to $16 \mathrm{MPa}$ at $500{ }^{\circ} \mathrm{C}$, the extention grows from $0.5 \%$ to $28 \%$, respectivily ;

-at $500{ }^{0} \mathrm{C} \&$ rate variation in $(0.35-1.4)^{*} 10^{-3} \mathrm{~s}^{-1}$ range does not affect the composite properties. 


\section{Referens}

1. Novikov S. A., Bat'kov Yu. V., Glushak B. L.

Study of destruction and resistance to plastic deformation of aluminium composite under dynamic loading. Methods.

( 1 stage of 003 task of contract 0002P0004-94). Arzamas-16, 1995.

2. Korshunov A.I., Kravchenko T.N., Saveleva O.M.\,

Plotting stress-strain diagrams by recalculation of the computer diagram Strength Mater.-1982-v14, N9 p.1268-1271. 
Test samples

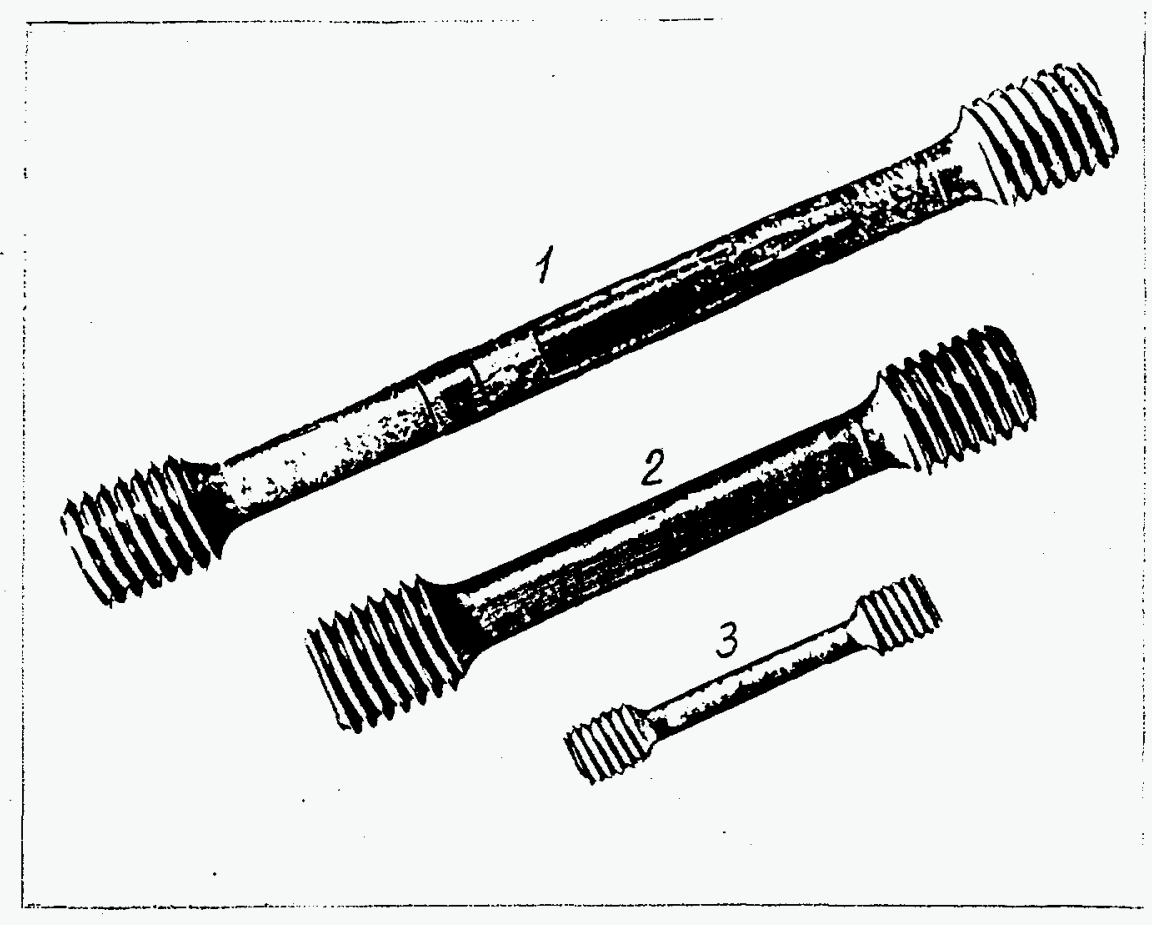

Fig. 1

Dependence of mechanical characteristics of aluminium composite on temperature and sample cut direction.

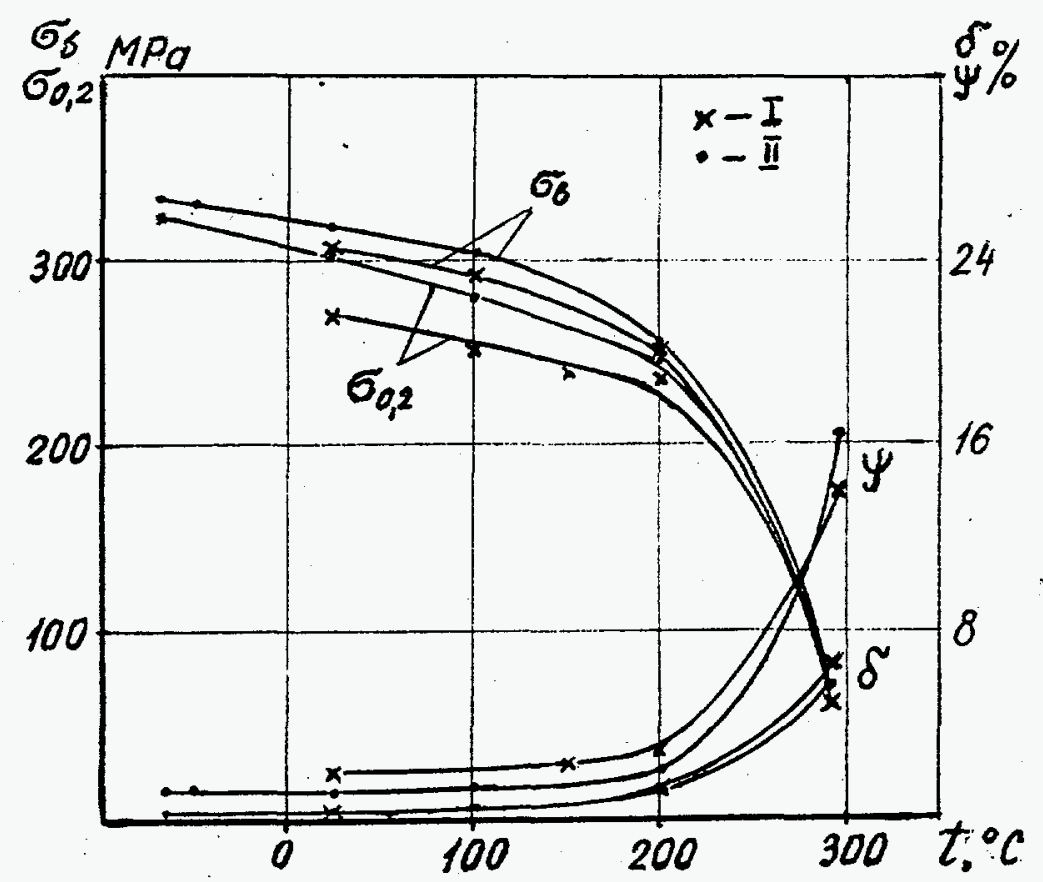

Fig. 2 
Aluminium composit extension diagrams of different temperatures.

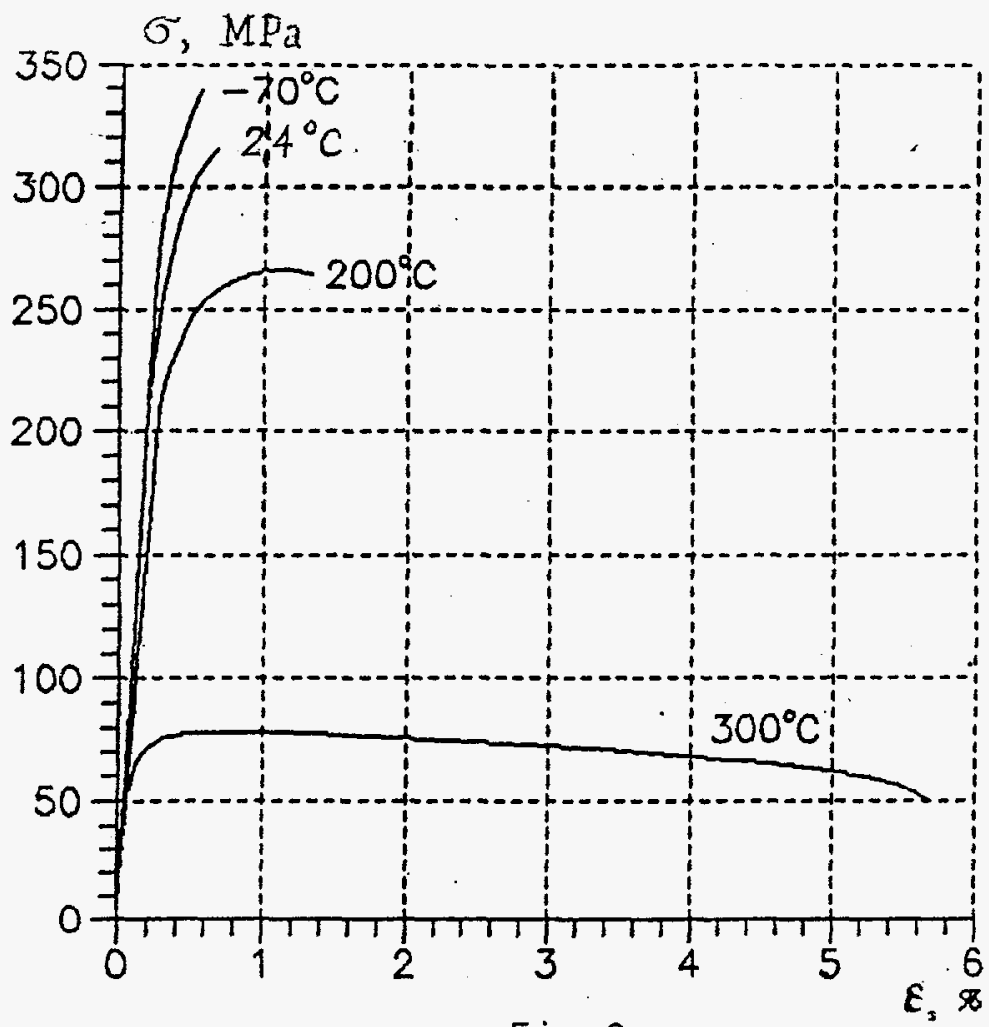

Fig. $3 . \mathrm{a}$

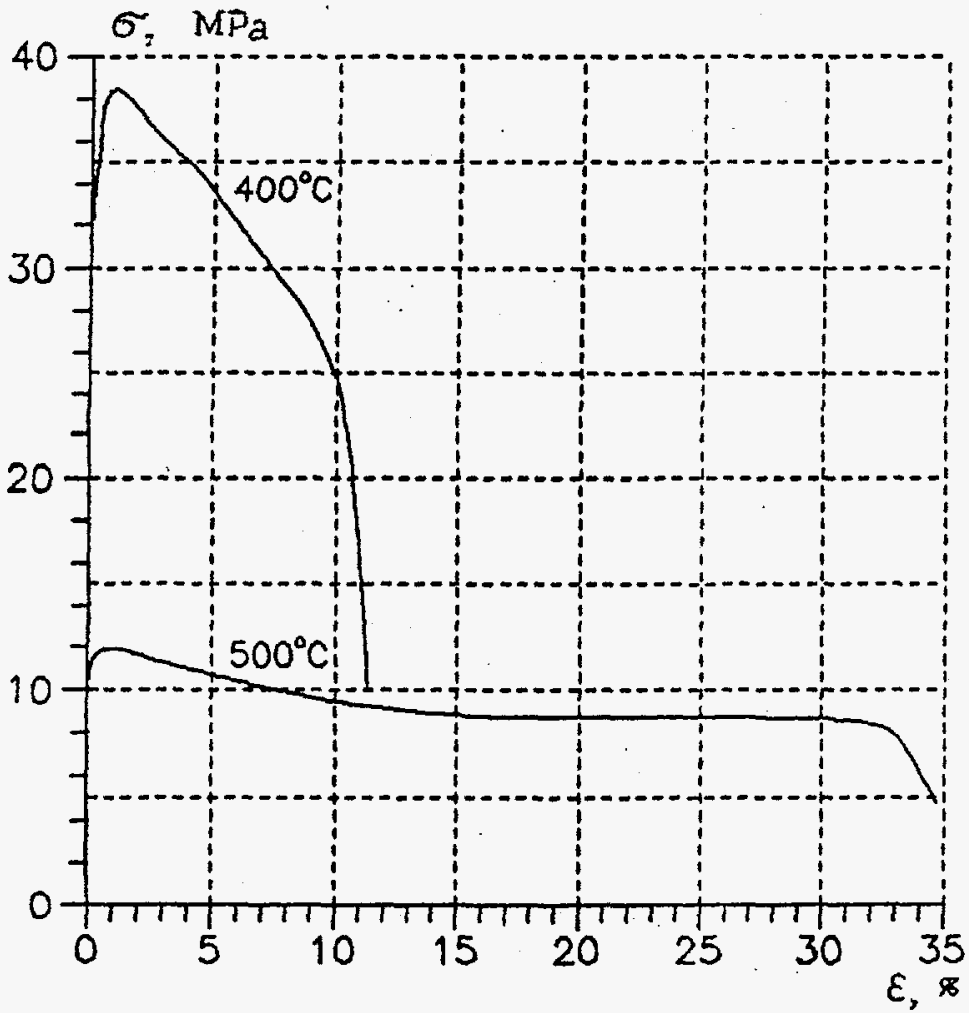

Fig. $3 \cdot b$ 
Blank Cutting Geometry for Sample Fabrication

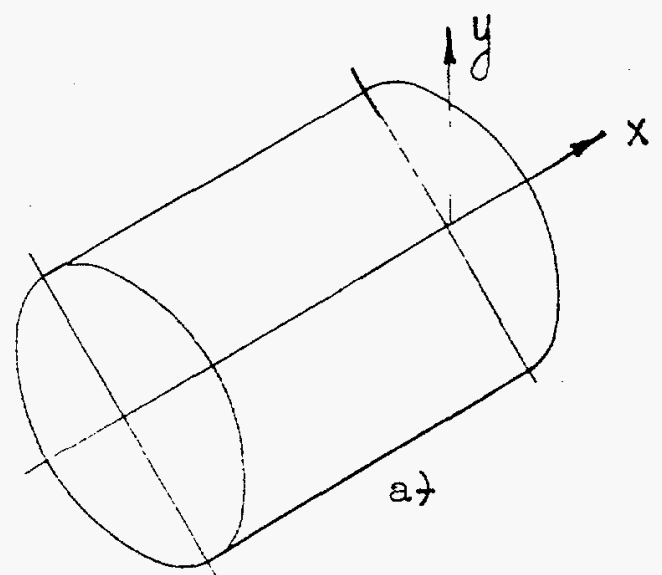

$x_{3}+30$
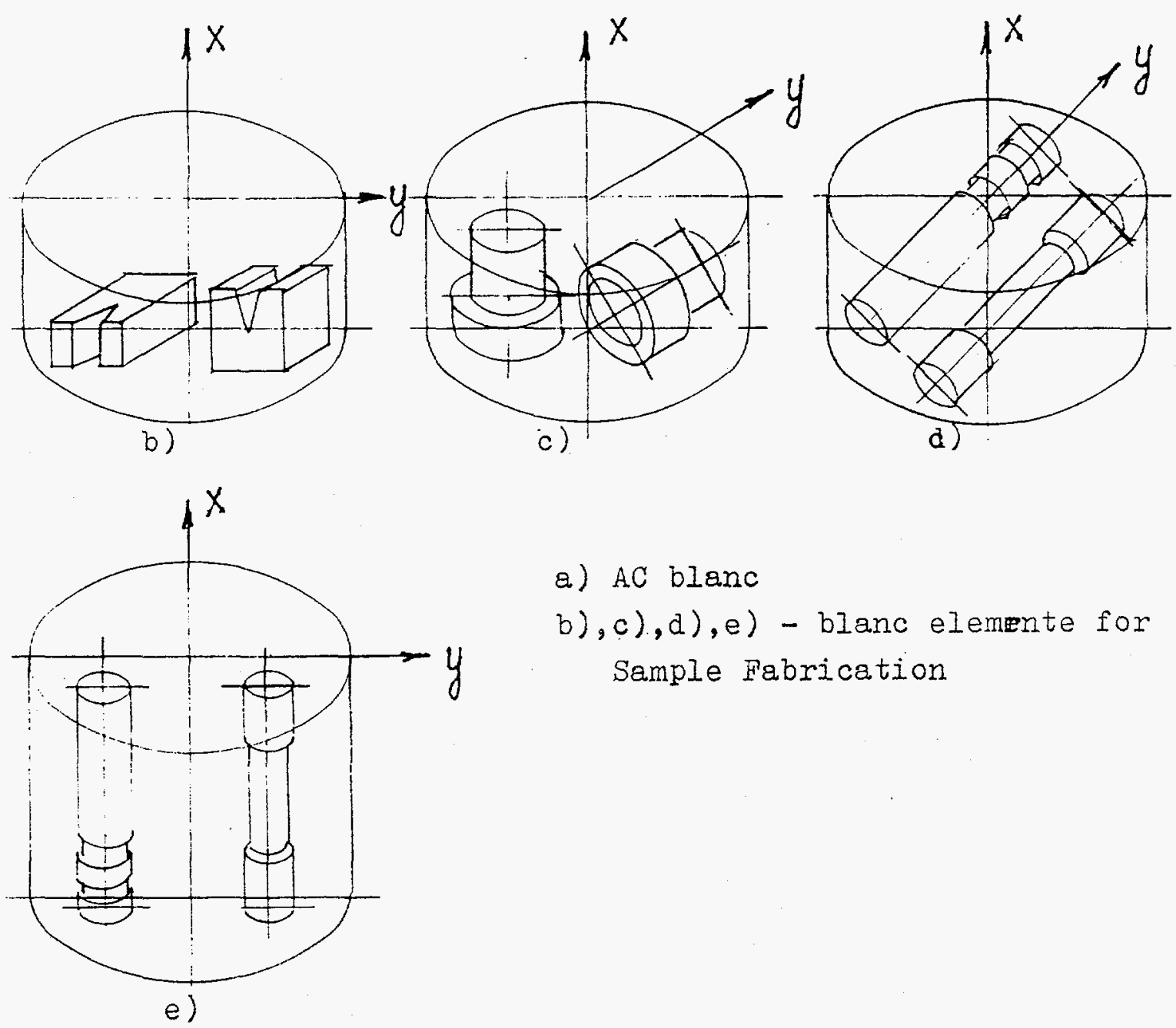

a) AC blanc

b),c),d),e) - blanc elemmte for Sample Fabrication

Fig. 1 
barle photomaphes for donamic property atudy

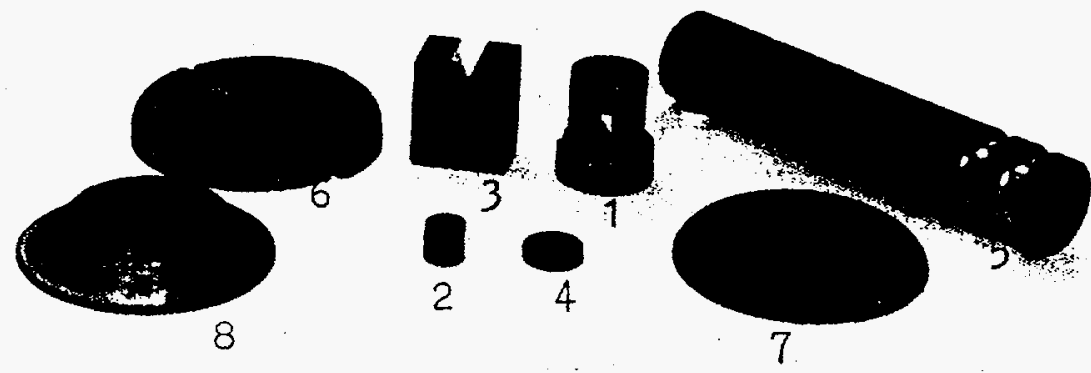

$\because$

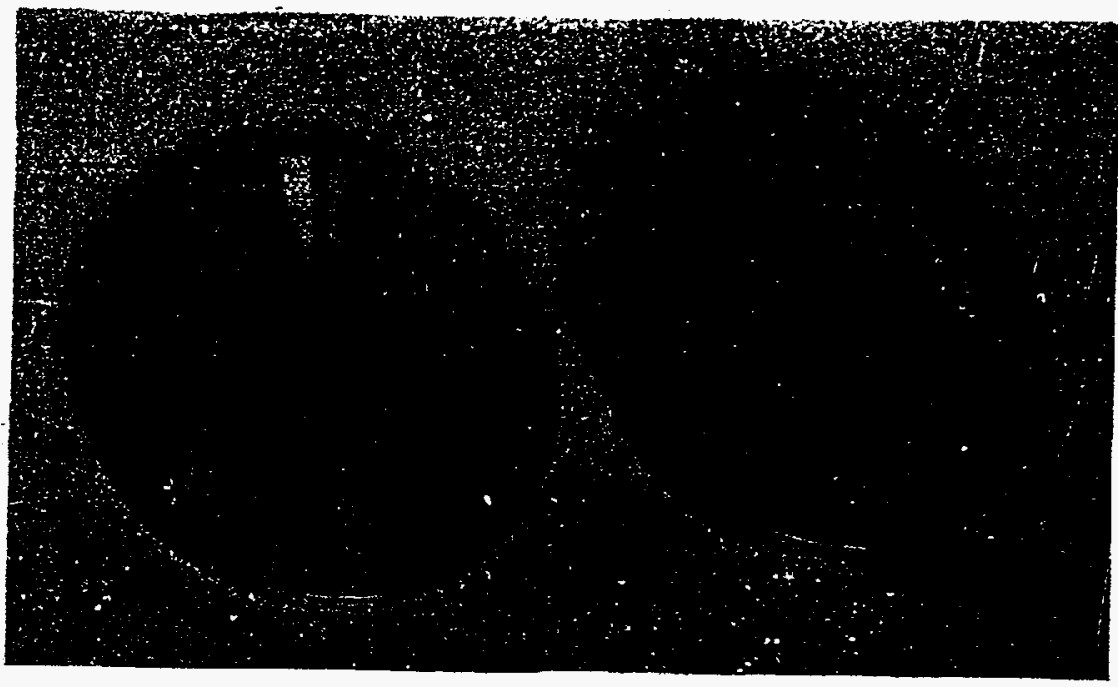

1 -tersion

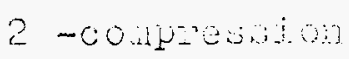

3 - sxcicistance

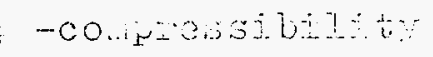

5 - ultinate yield $c-\} \quad \pi \sec i$

$8-7$

, -<smiles>[14CH2][14CH]=[As]</smiles> 
Cutting of Witners-Sampler for iletallographical Study

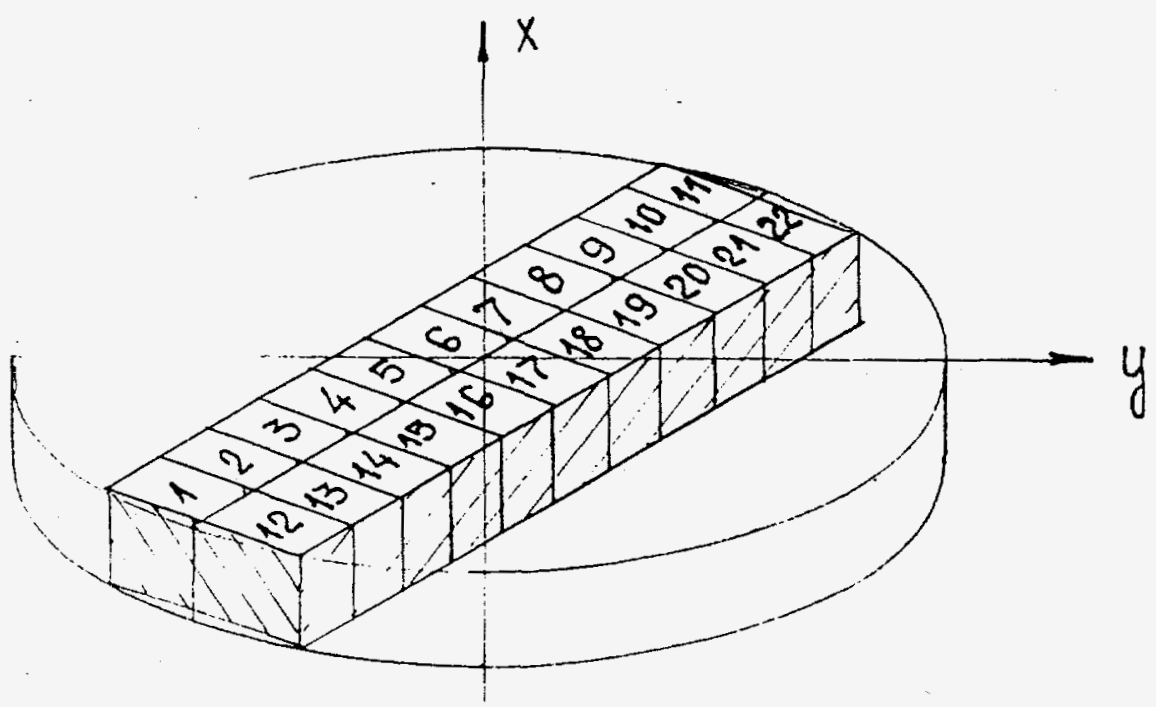

Sample surfeces wicrosection norication?

Sampler $1-11$ - as receibed
Sampler $12-22$ - apter thermal treatment

$\mathrm{ir} i \mathrm{~s} \cdot 3$ 
a)

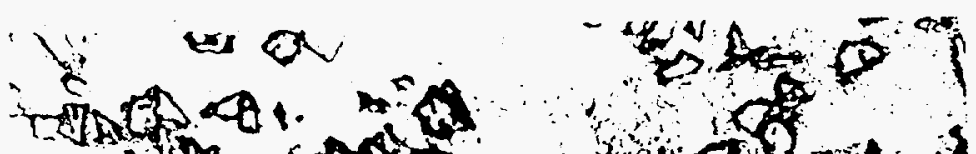

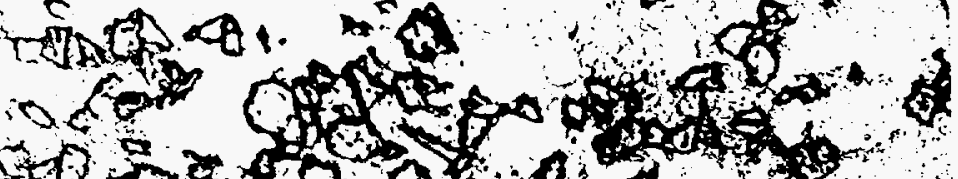

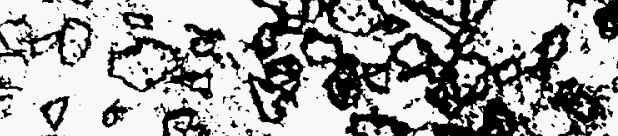

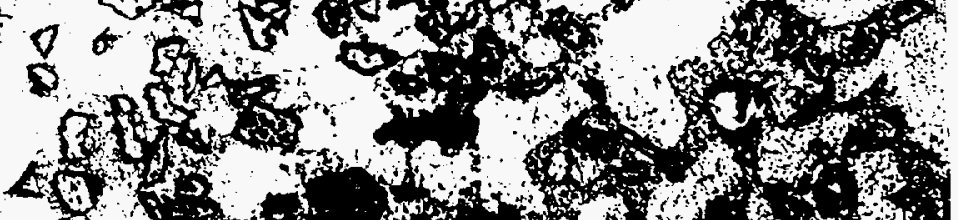

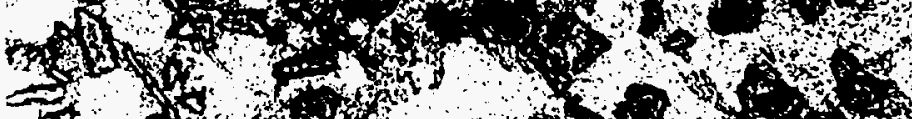

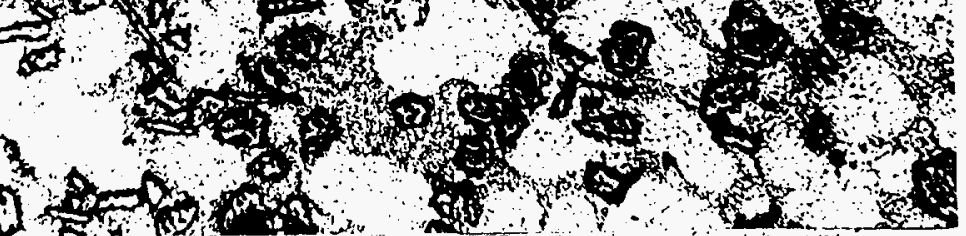
D.

b)

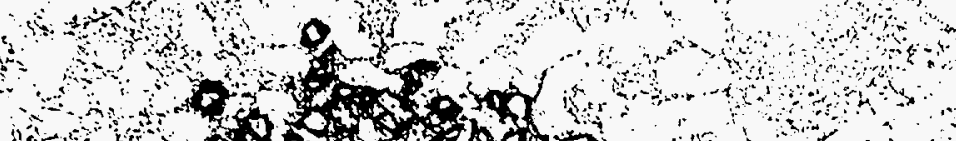

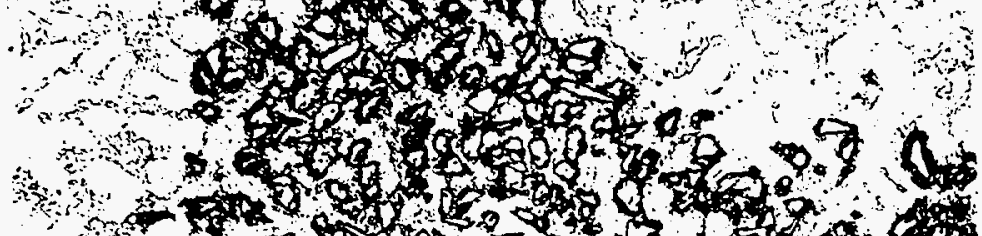
of

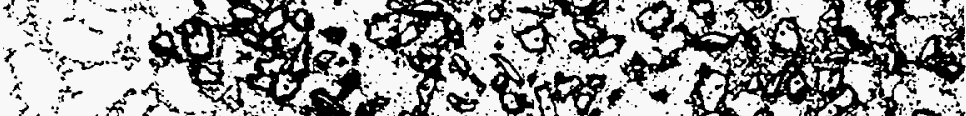
to

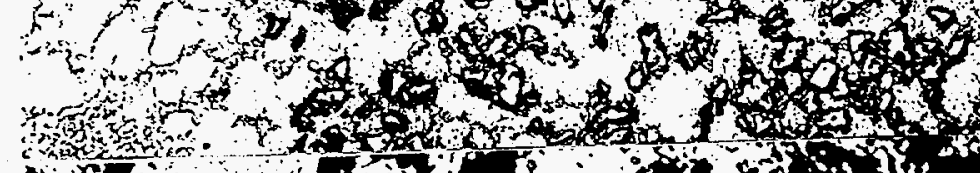
Solid solition of Iuminiun with sizicon Avtectics of sluminium wi.th silicon

Particks j.n aluminiua basis

c)

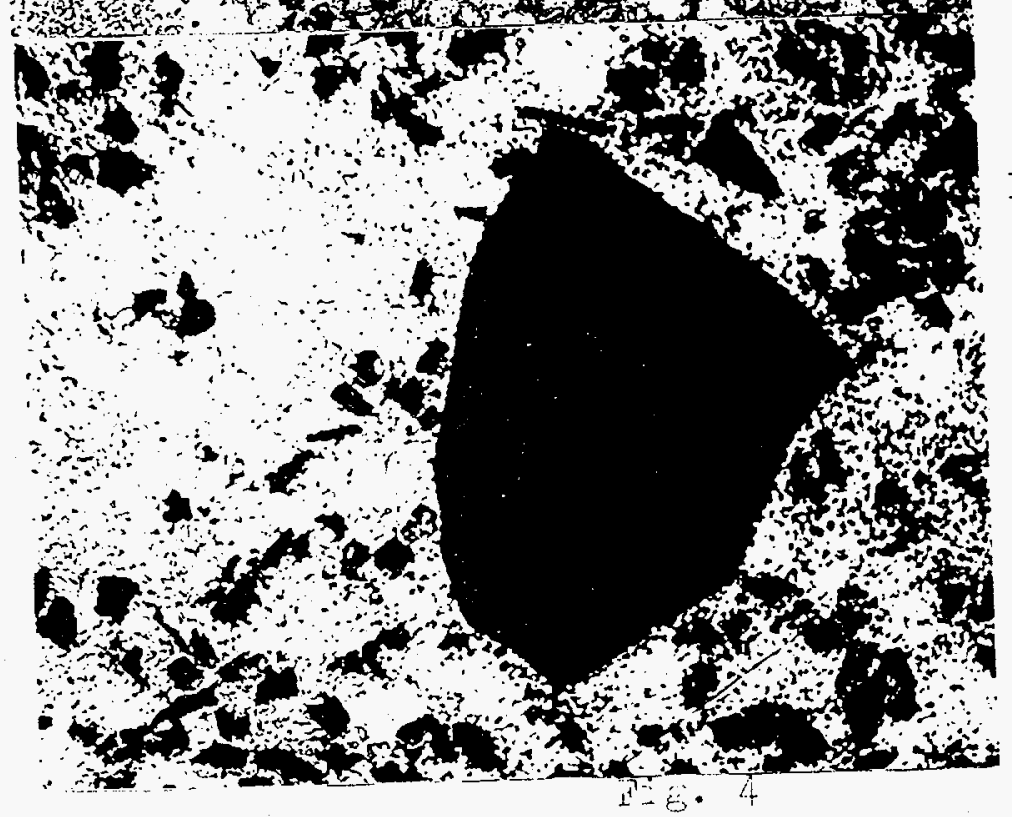

Large partick 


$$
S \cdot 8 T^{2}
$$
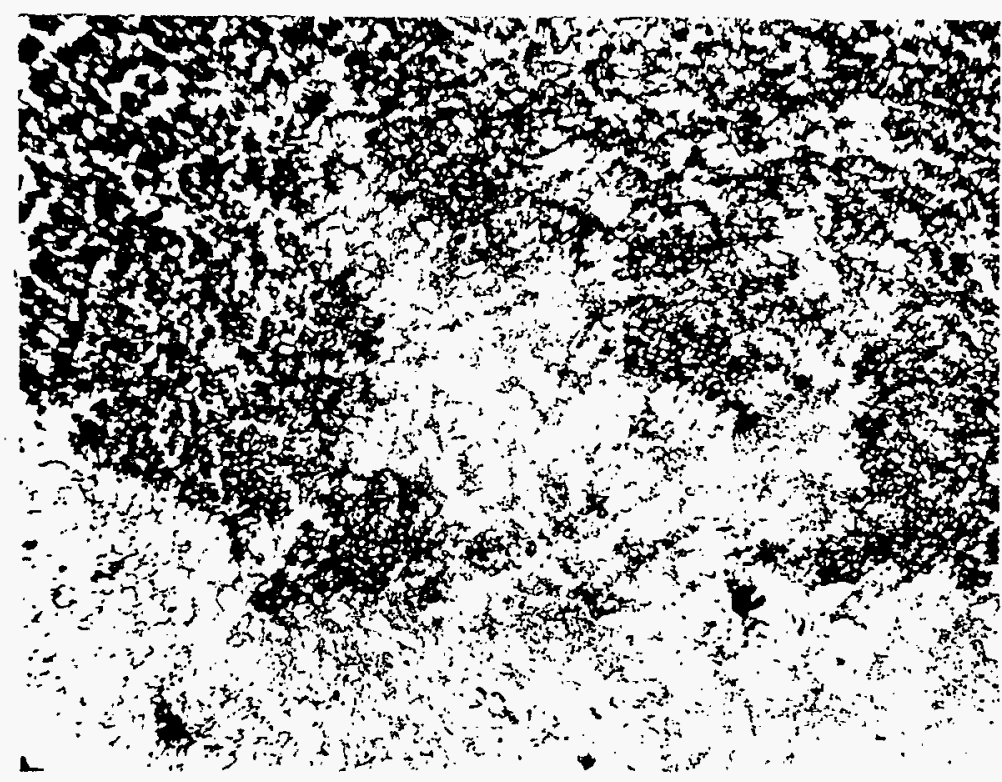

757 nout TM

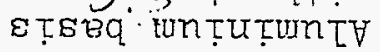
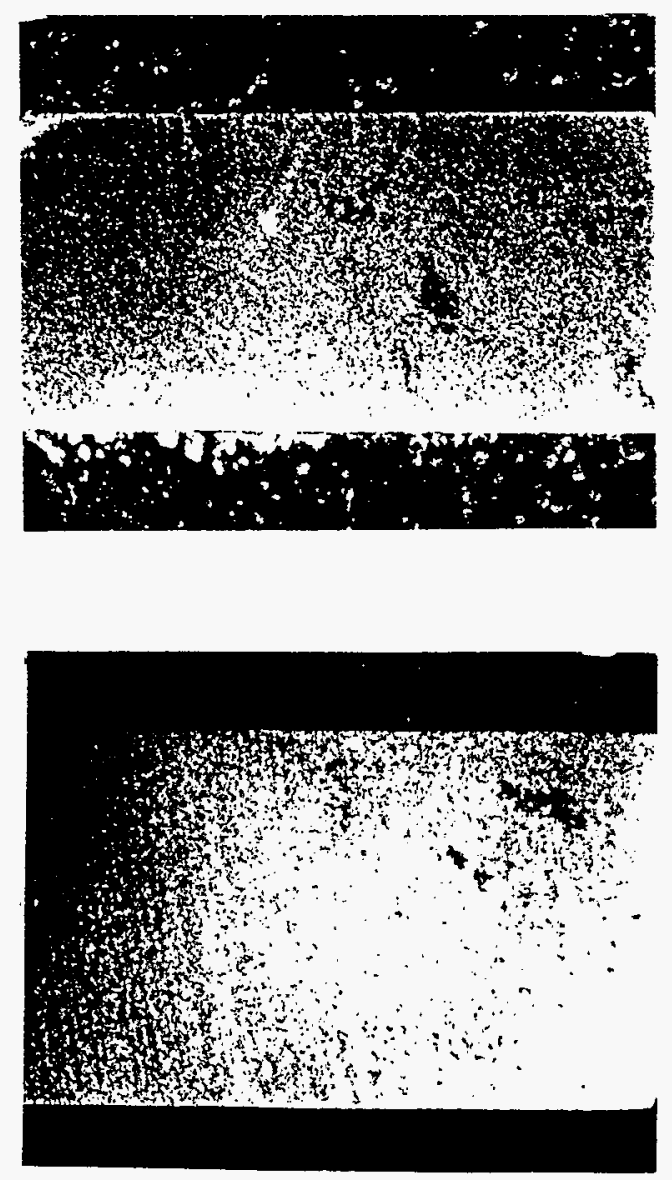

oxnfonxqsoxo?f:
J) 7 noप7TM

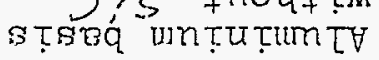


$\therefore:$ : inaric tension, $\dot{\mathcal{E}}=200 \mathrm{~s}^{-1}, \mathrm{~T}=25^{\circ} \mathrm{C}$

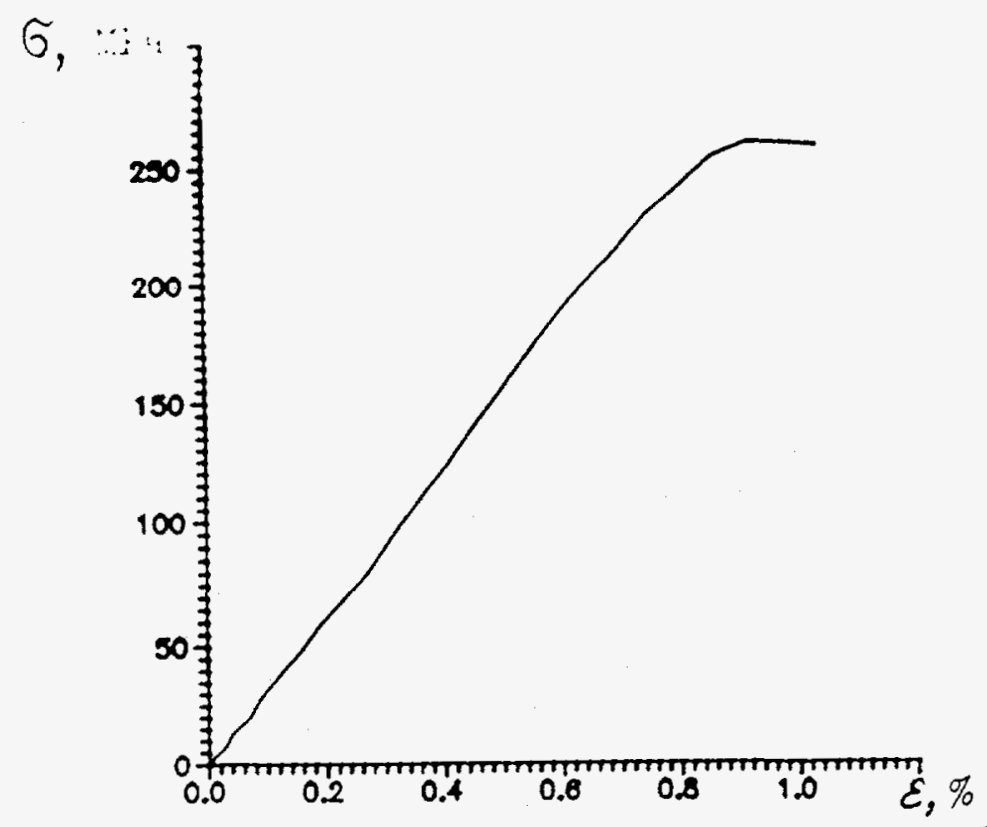

a) diagram of stress-strain $\sigma-\varepsilon$

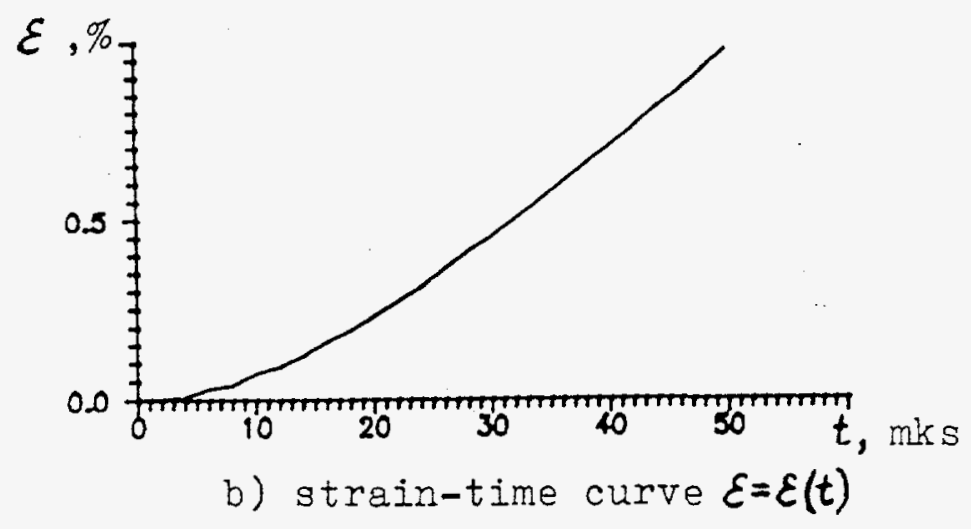

Fig. 6 


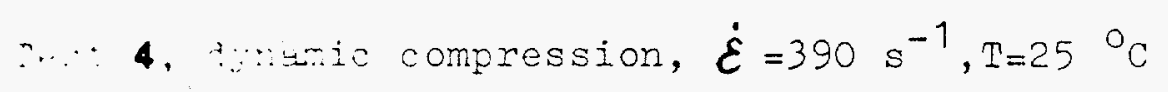

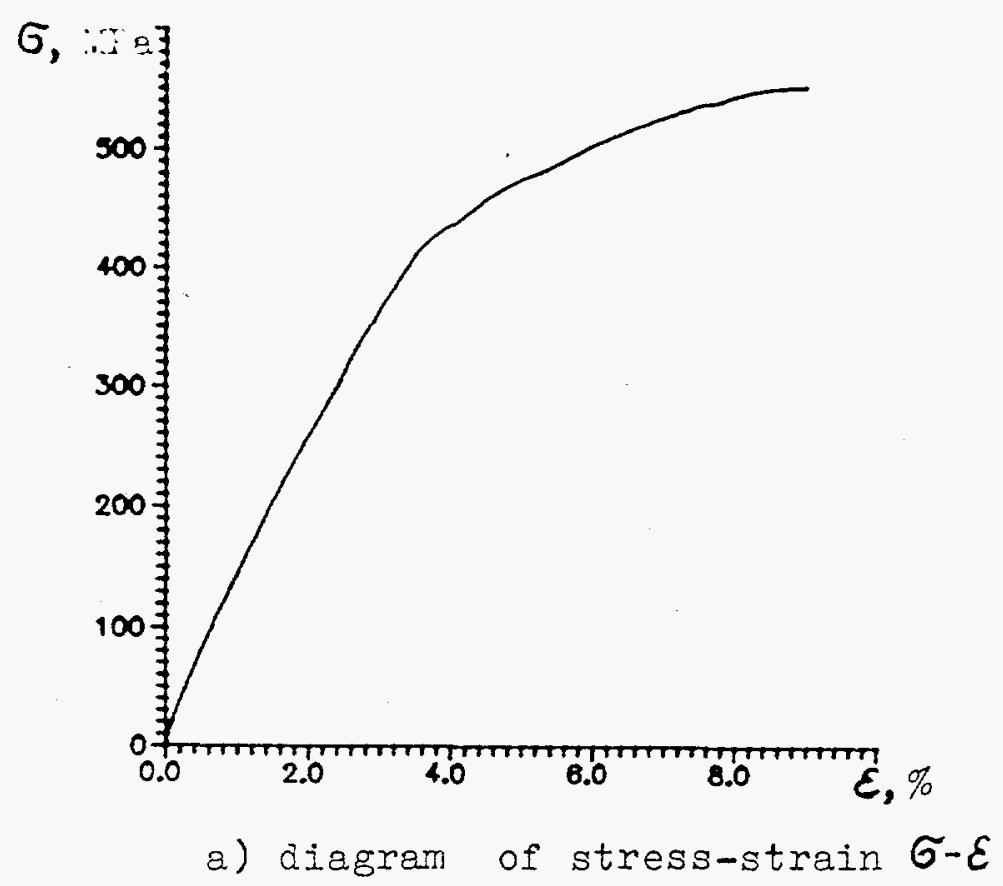

m

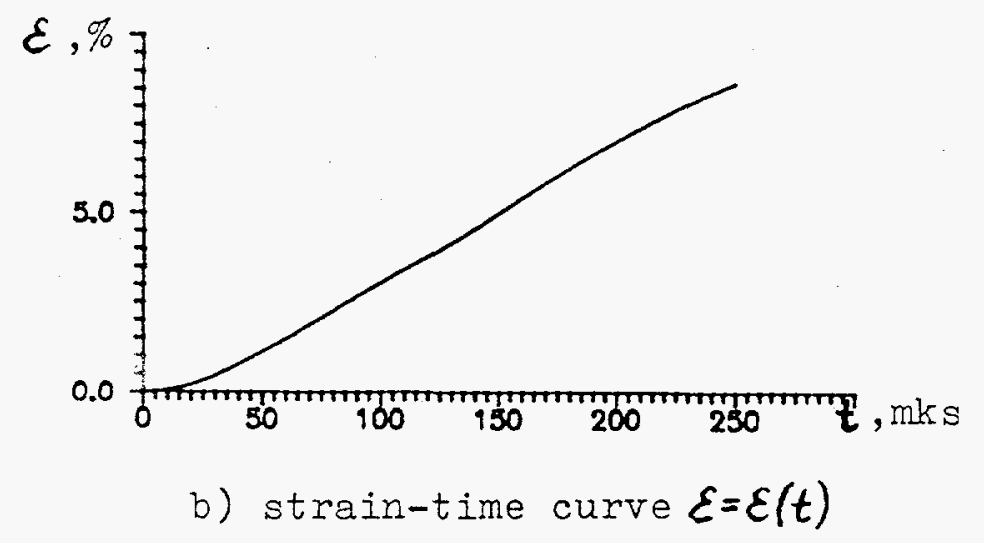

Fig. 7 
Test 5. crack resistance, $\bar{\nabla}=1,40 \cdot 10^{4} \mathrm{~s}^{-1}, \mathrm{~T}=25^{\circ} \mathrm{C}$

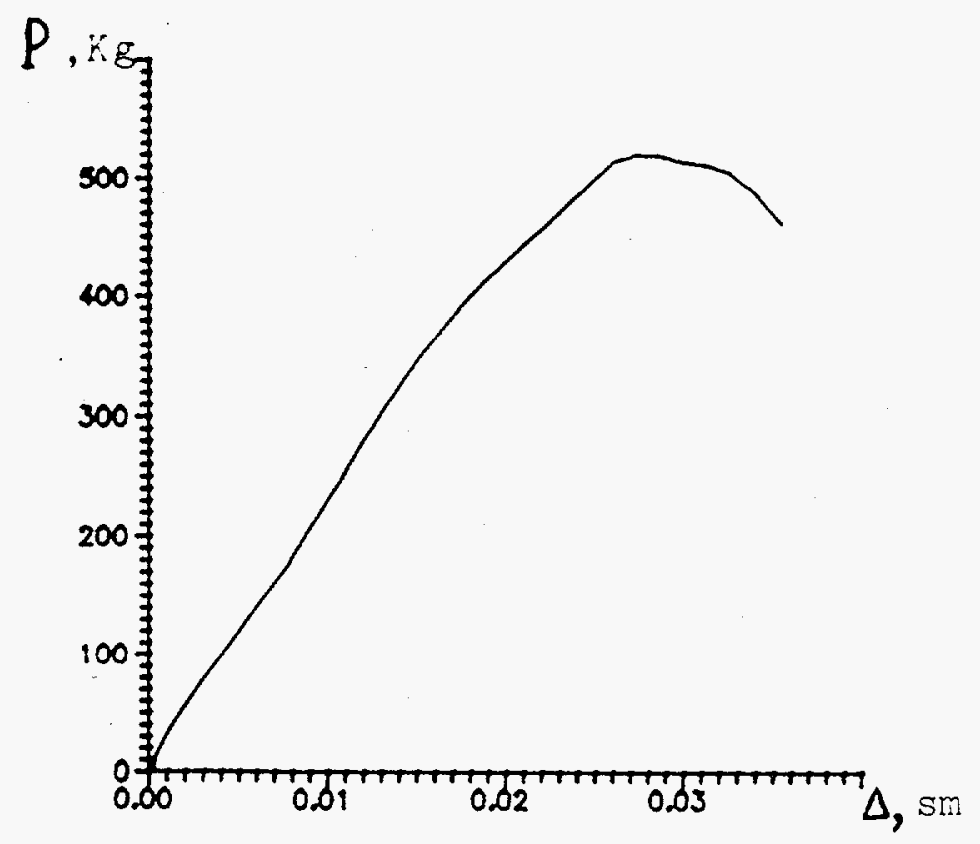

Fig. 3. 
अ०

$\mathrm{U}_{S}-{ }_{r}-\ldots s_{g}$ rai: for Aluminium Composite

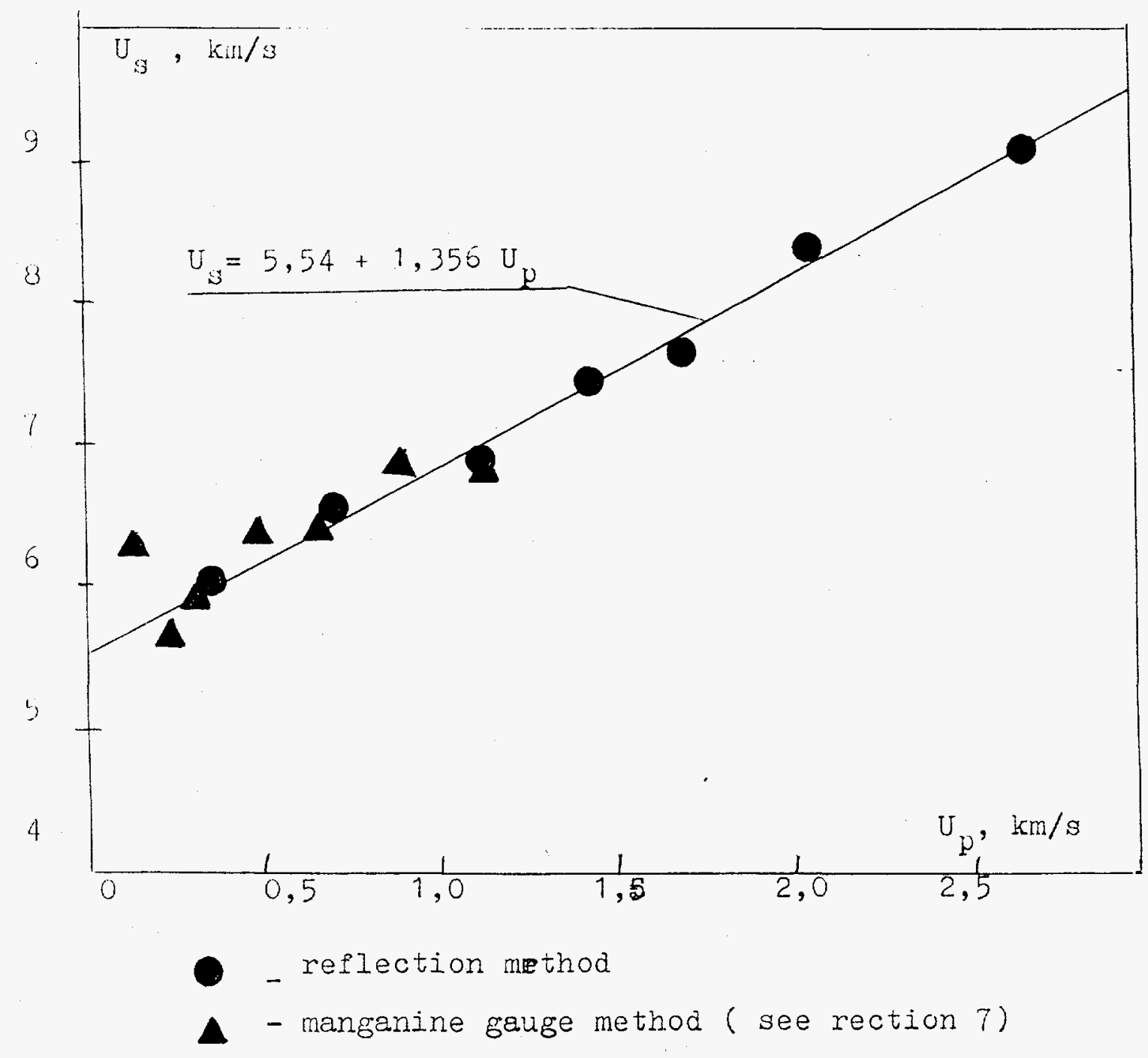

rig. 9 
Aluminium Composite Samples before before and after Impact

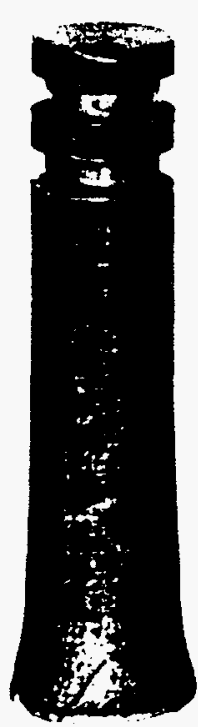

$\mathrm{wW}, \mathrm{m} / \mathrm{s}$

170

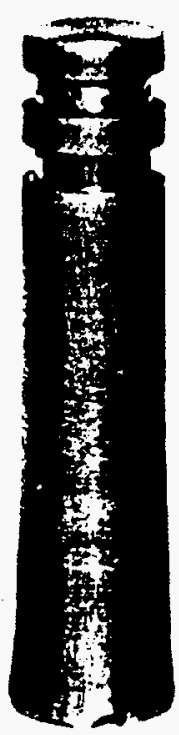

155

Hig. 10

Calculation Results

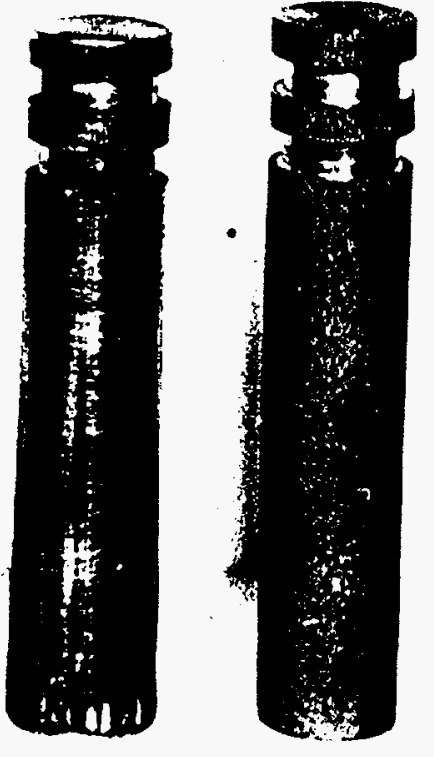

110
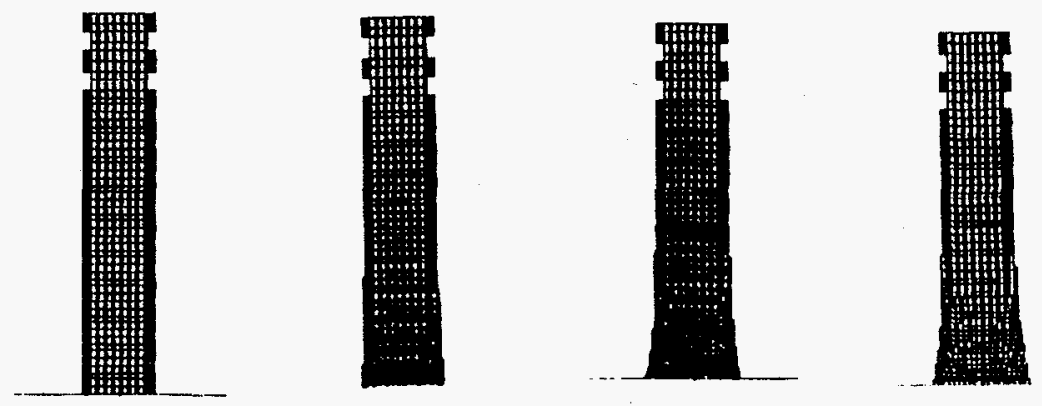

$w_{0}, \mathrm{~m} / \mathrm{s}$

170 
Hain staeso vocilldarams

-a)

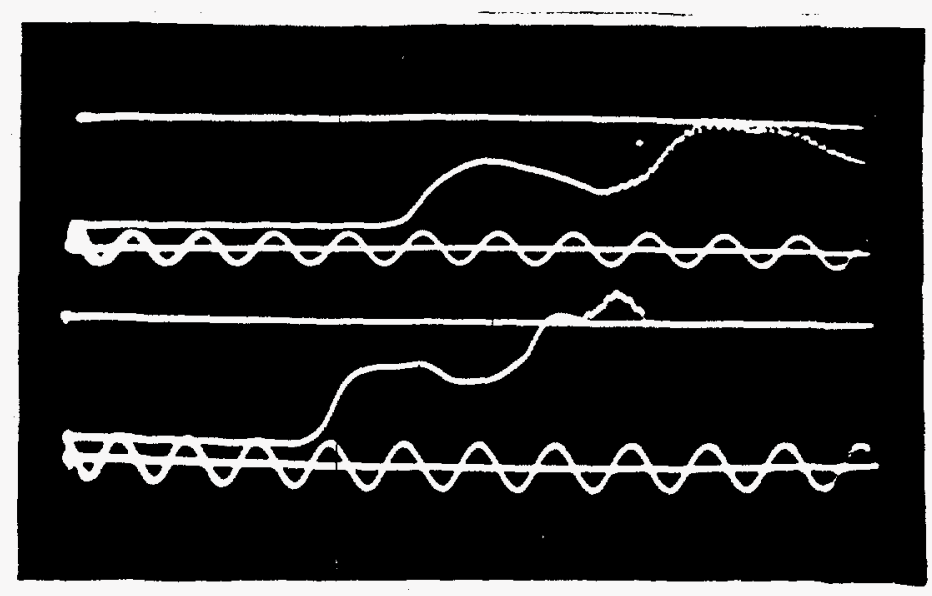

$\widetilde{\sigma}_{\mathrm{y}}=2,0 \quad 1 \mathrm{i} / \mathrm{l}$

$\sigma_{\mathrm{x}}=2,4$ il'a

b)

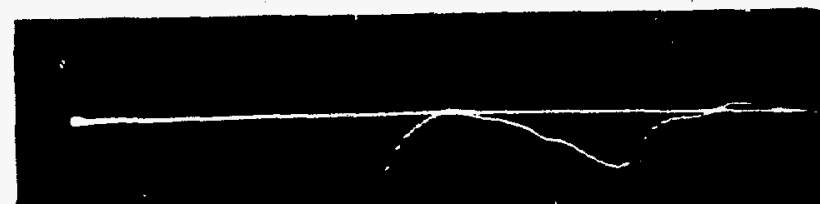

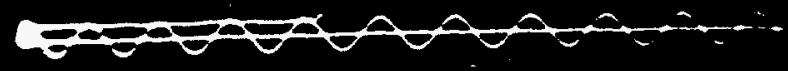

$$
\begin{aligned}
& \sigma_{y}=3,3 \\
& \sigma_{x}=3,6 \text { (ild }
\end{aligned}
$$

c)

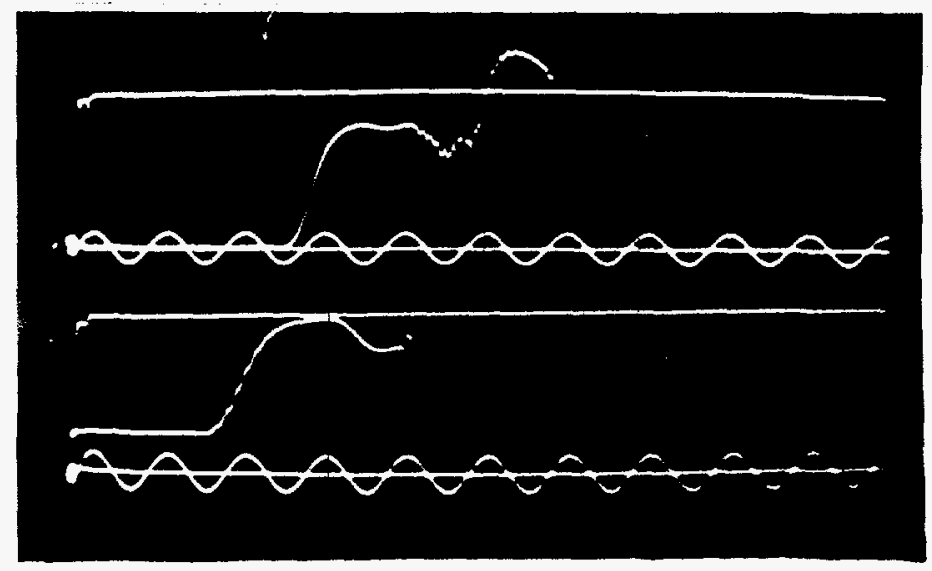

$\dot{\sigma}_{\mathrm{y}}=3,6 \quad \mathrm{i} \mathrm{l}^{\prime \prime \mathrm{t}}$

$\sigma_{\mathrm{x}}=3,8$ (in

Tine inten... - : us 
inain Stres Gocillogram

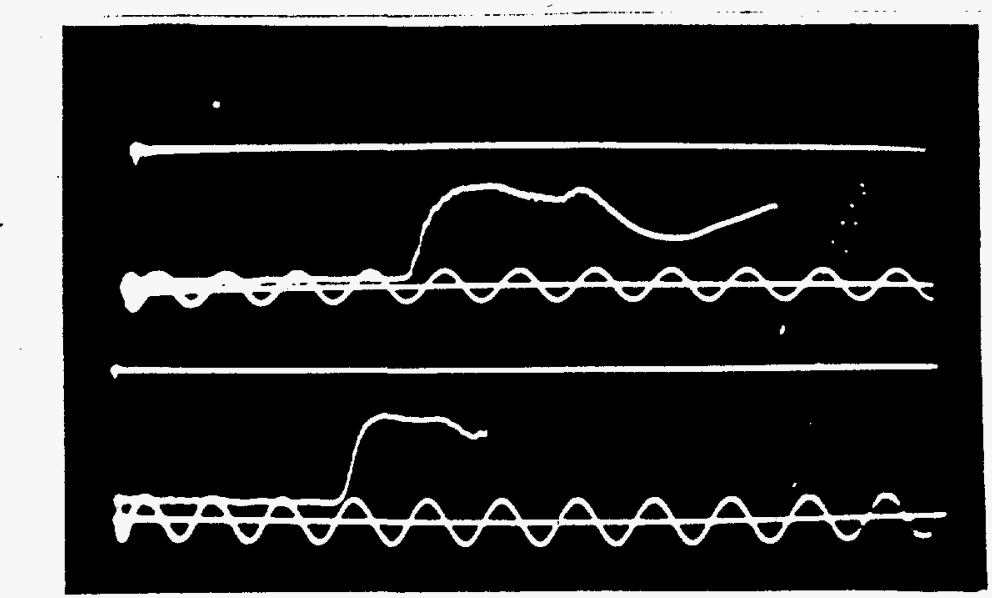

$\sigma_{\mathrm{y}}=4,7$ (iper

a)

$\sigma_{x}=4,9$ lipa

s.

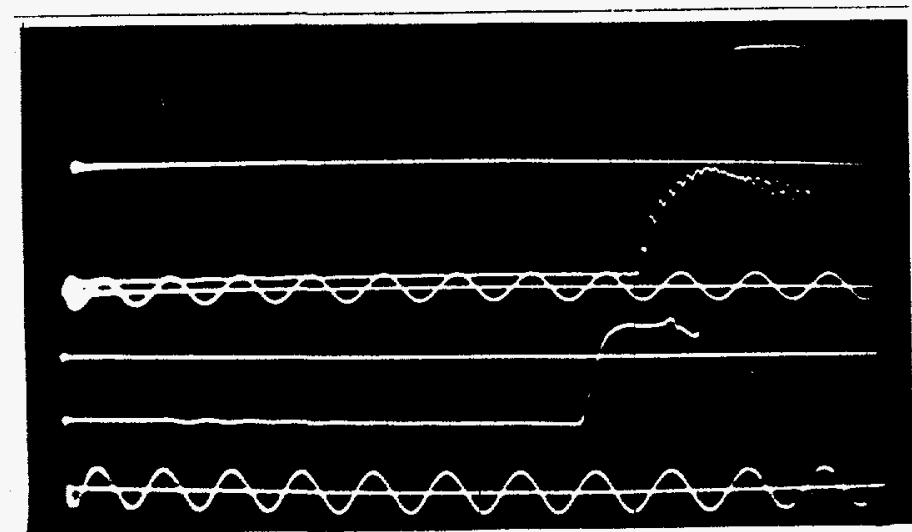

$\sigma_{y}=12,8\left(\mathrm{~d}^{\prime} \mathrm{t}\right.$

b)

$\sigma_{x}=13,0$ Ga

c)

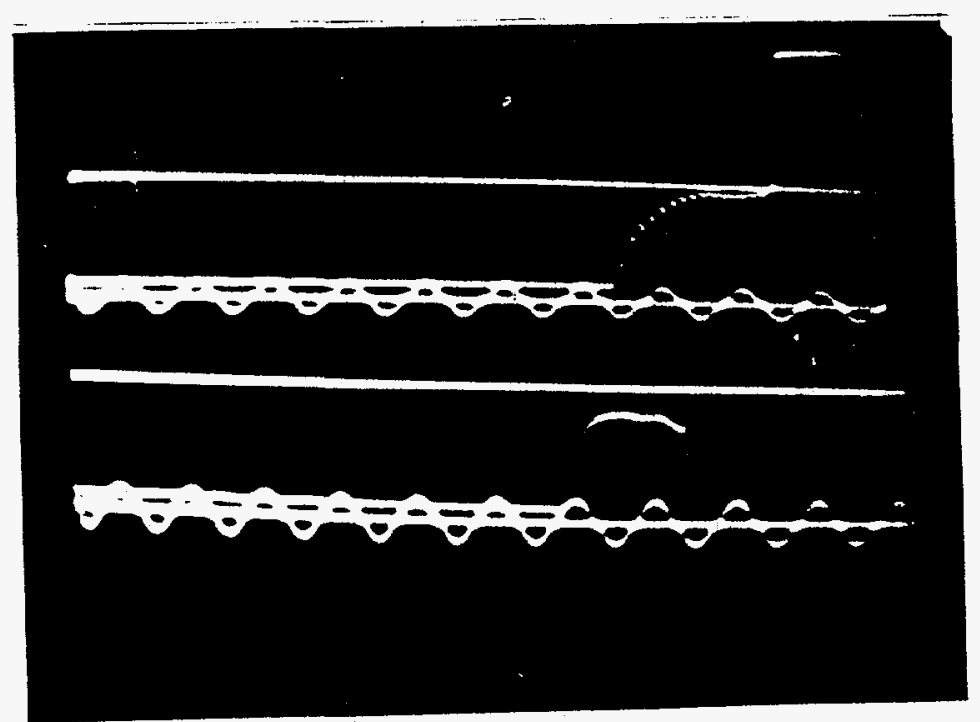

$\sigma_{y}=11,3$ (illu. $\sigma_{x}=11,1$ (i)t.

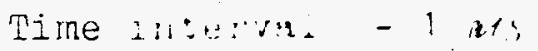


Main Stres: Oscillograms

a)

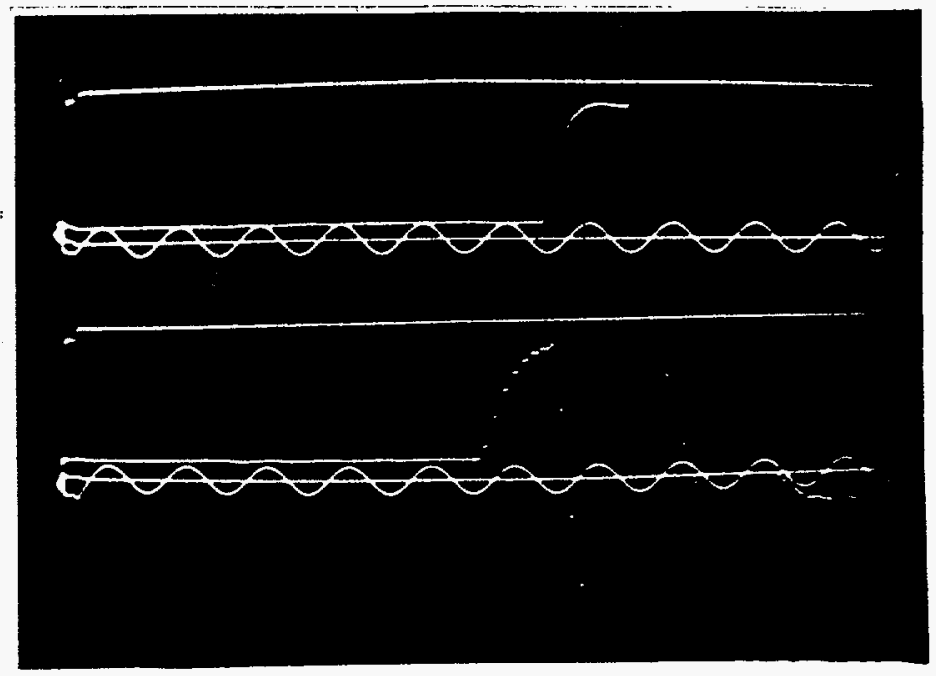

b)

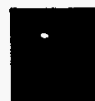

5.5

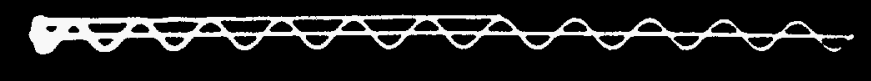

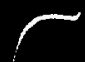

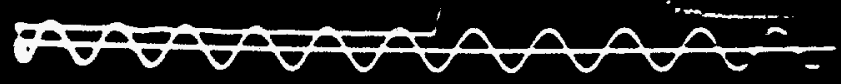

c)

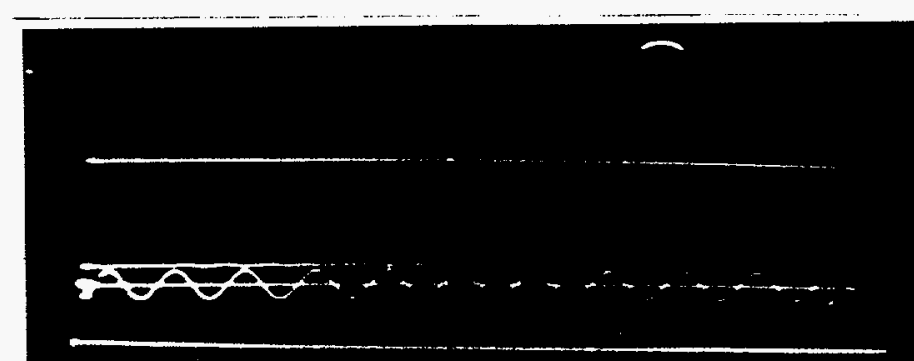

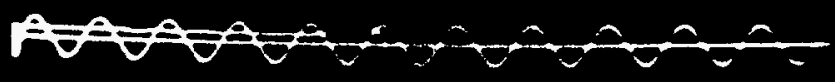

$Q_{x_{2}}^{v}=11,1111 \% 1$

$\sigma_{x_{1}}=16,8$ il'n

$\sigma_{y} \stackrel{\prime}{=} 10,6$ (it)

$\left.\vartheta_{x_{2}}=16,9(1)^{\prime}\right)$

$\sigma_{y}^{2}: 31,1,411$

$\sigma_{x}=: \because 1,: 11$, 


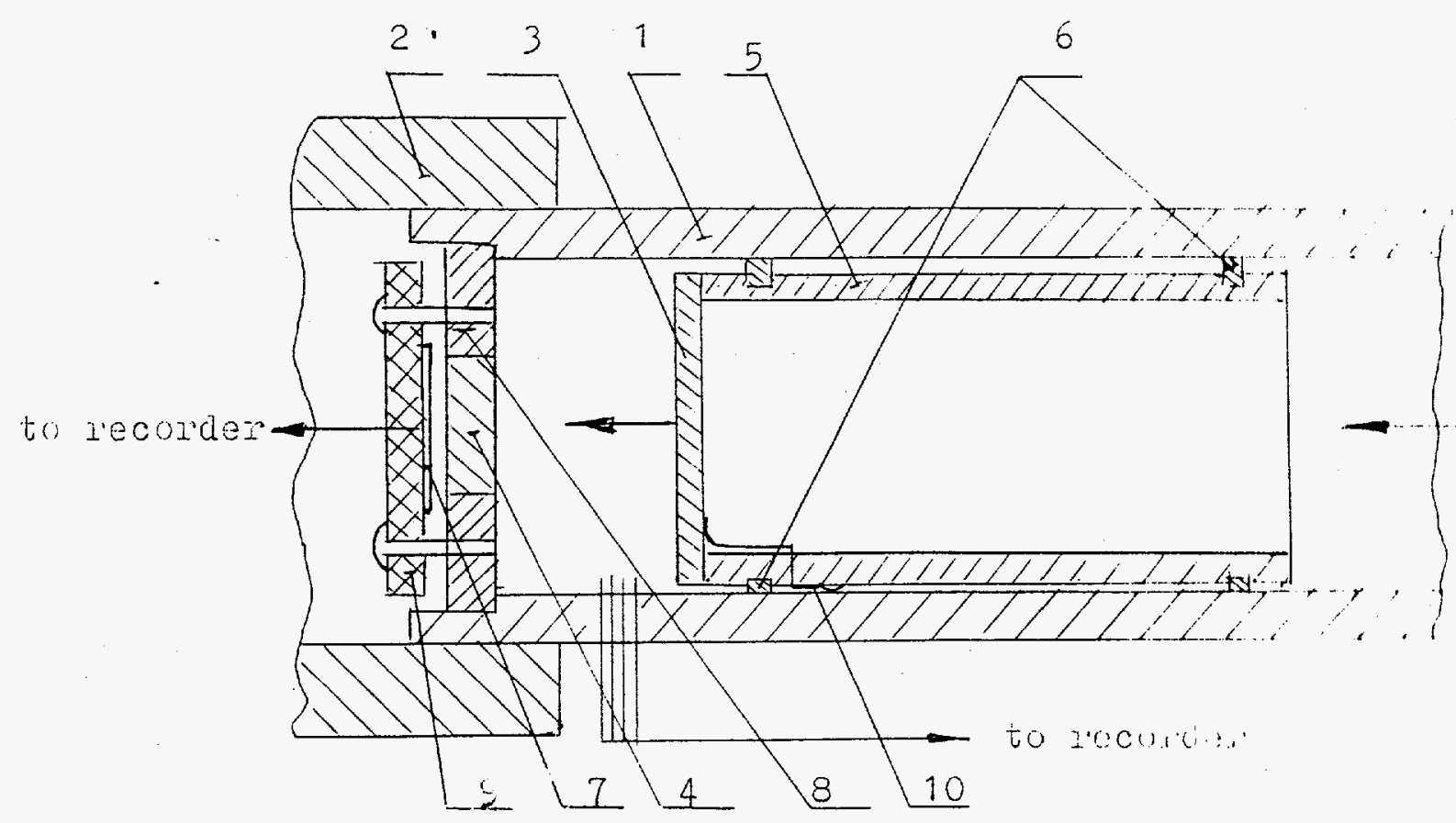

2. Braking chamber

3. Inpertor

4. Sample

5. Shell

6. Nluoroplastik rings

7. Capacitive gauge

8. Sample cartridge

9. Isolator

10. Inpaktor kontakt with fakility casing 
Pree surface velocity $\quad \Delta \mathrm{m}=5 \mathrm{~mm}$

3

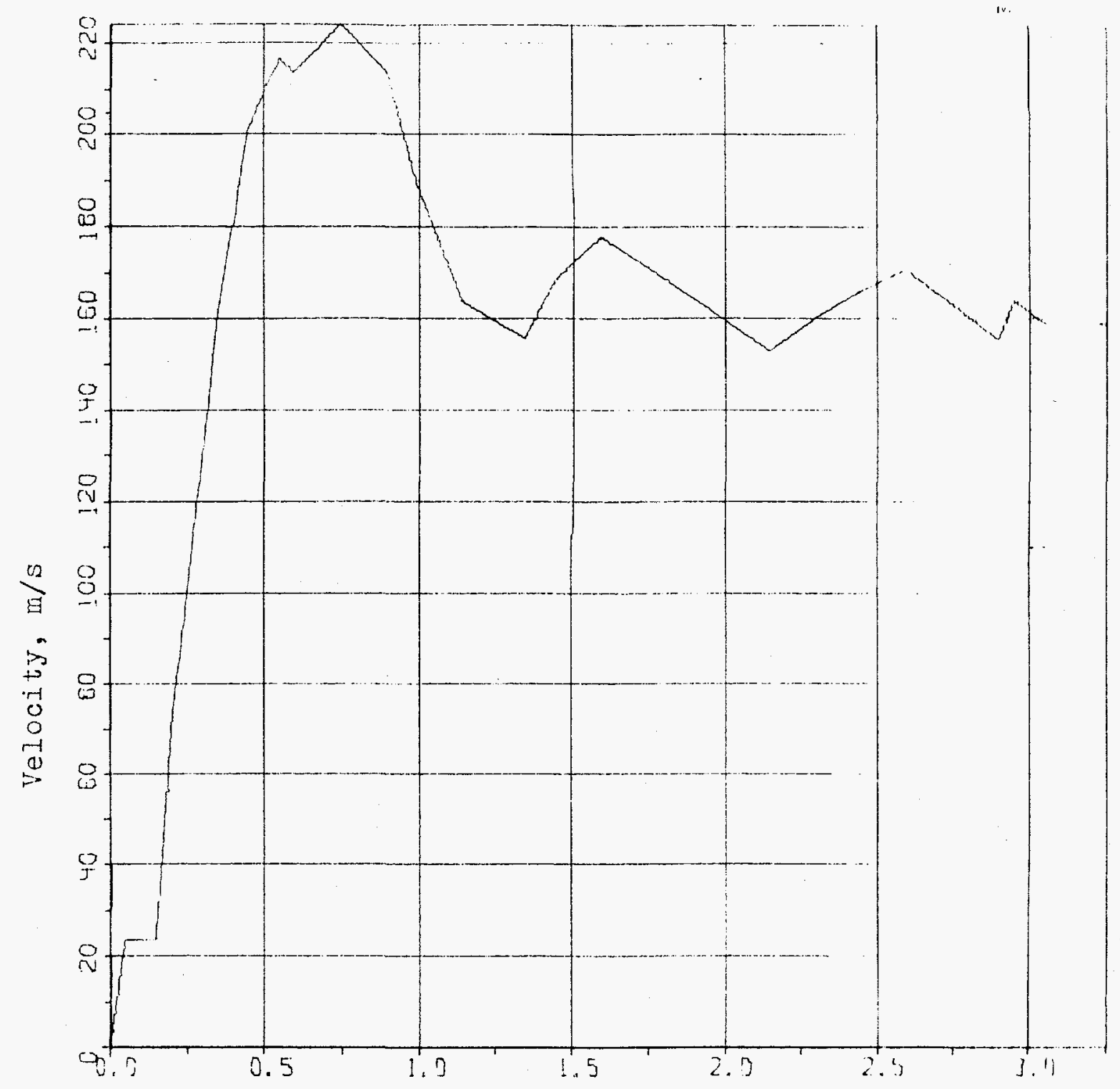

Time, mks

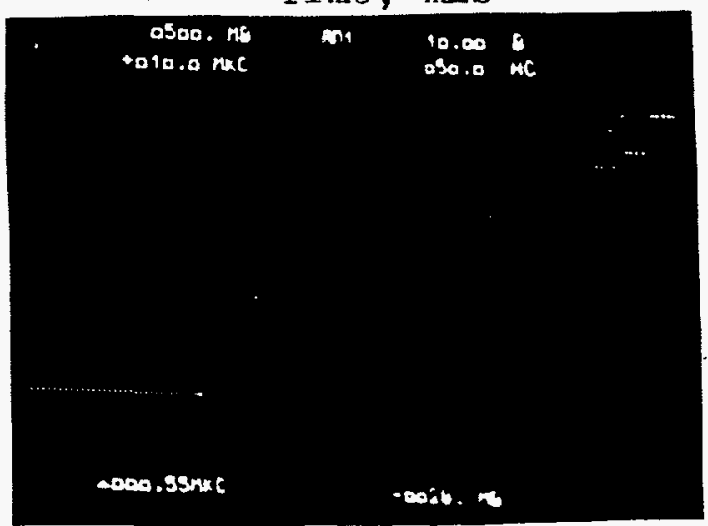

Capacitive geugi j $(: ;$ acillogram

$\therefore c$. 
Free surfece velocity $\Delta \mathrm{m}=10 \mathrm{~mm}$

$3+3$
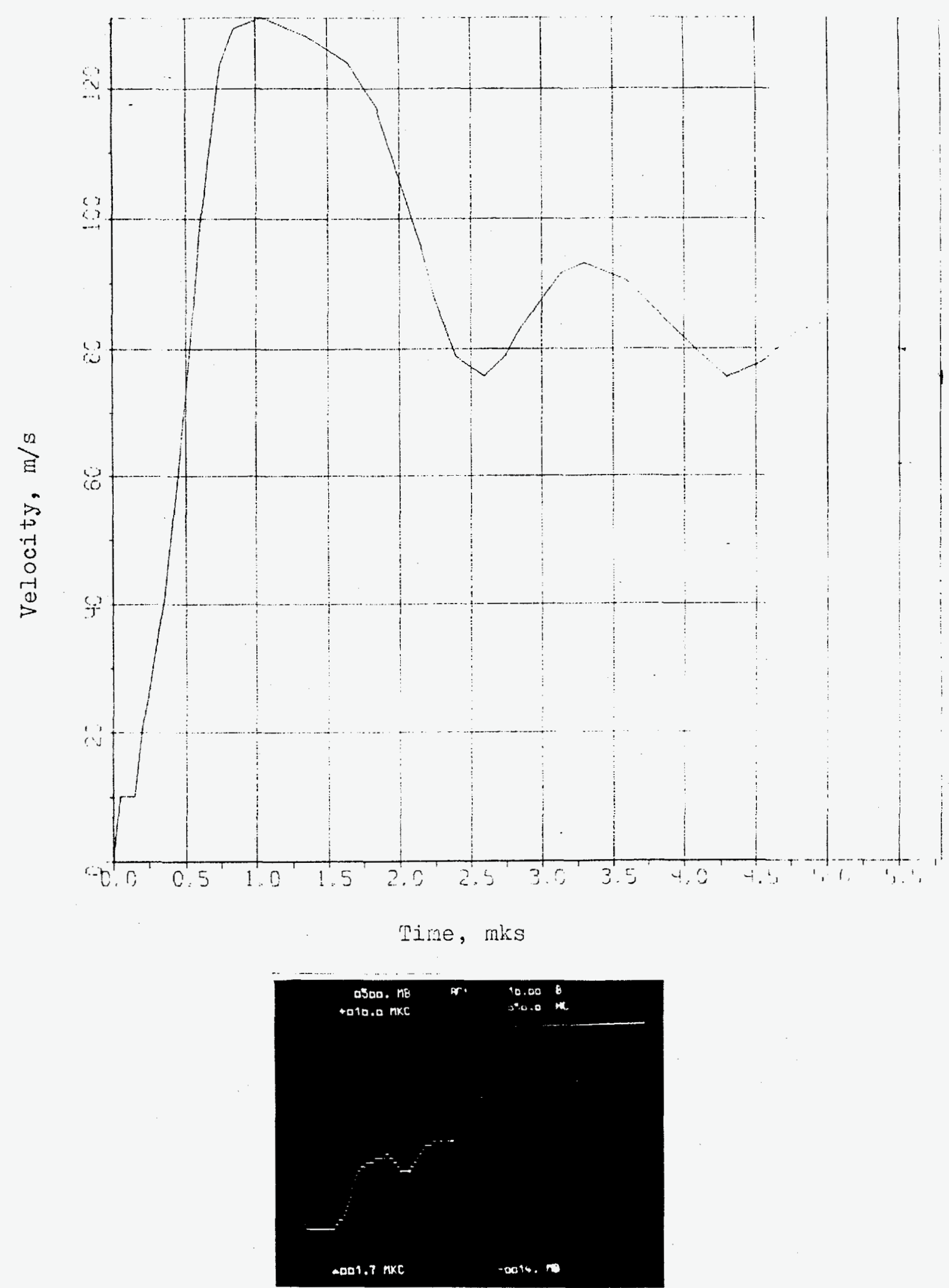

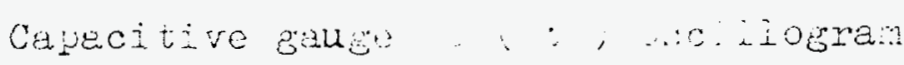

$\because-1 ; \cdot$ 


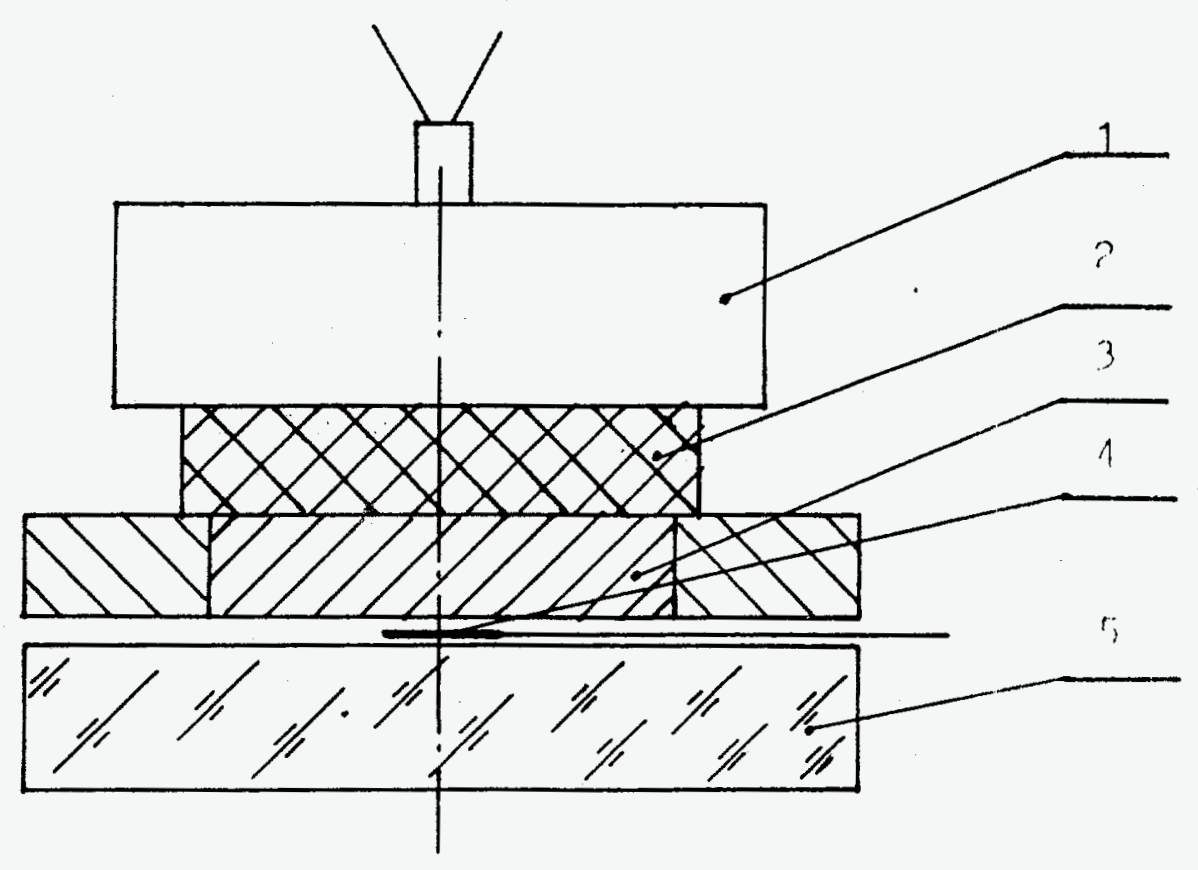

Fig.18. Experimental setup 
preliminary frame

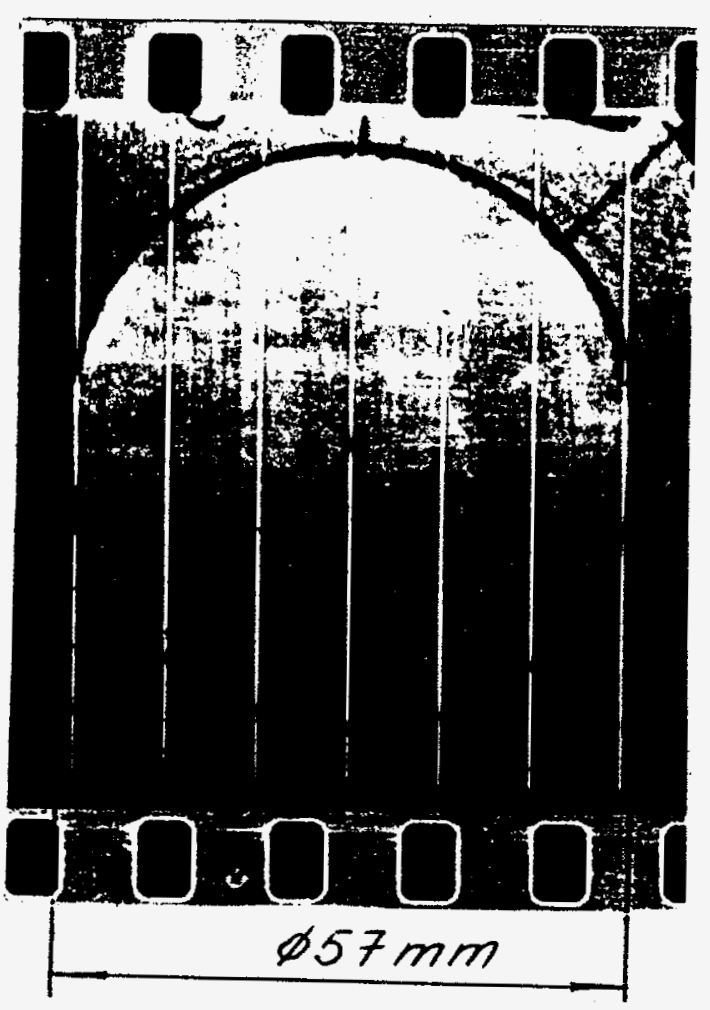

$$
V=3 \mathrm{~mm} / \mu \mathrm{s}
$$

frame under titu procesu

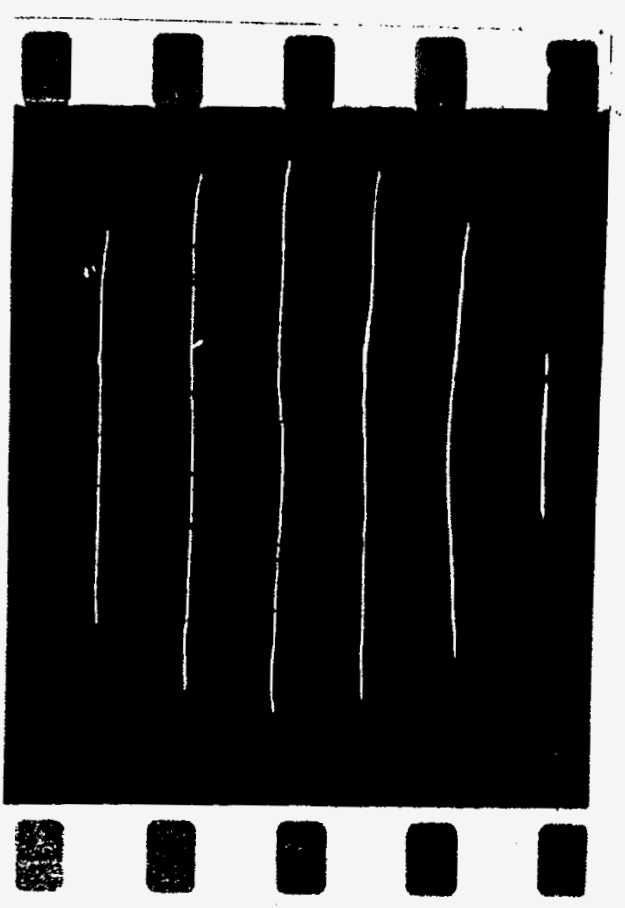

Fig.19. Detonation wave front photochronogrun 


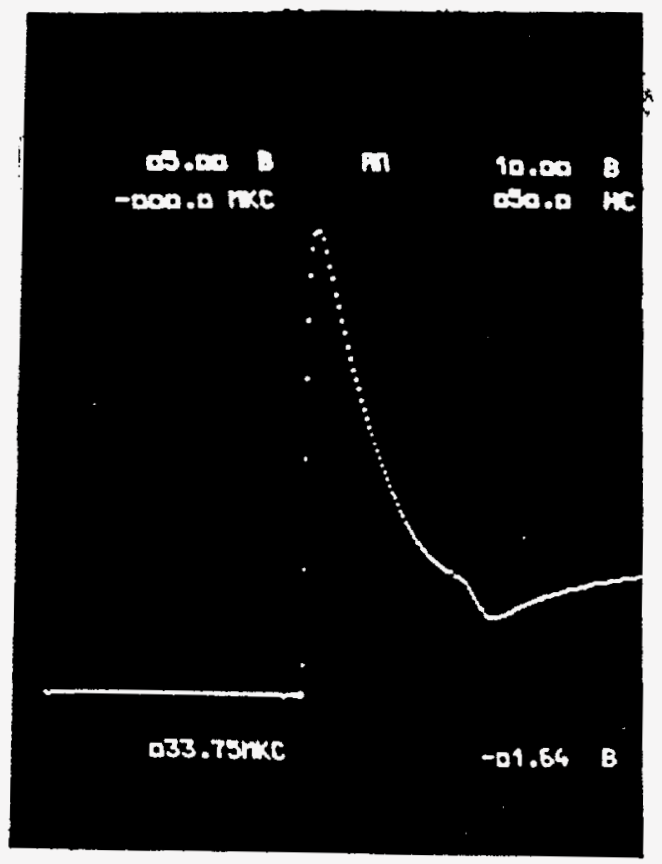

Fig.20. Oscillogram $\boldsymbol{G}(t)$ of the passing shock wave.

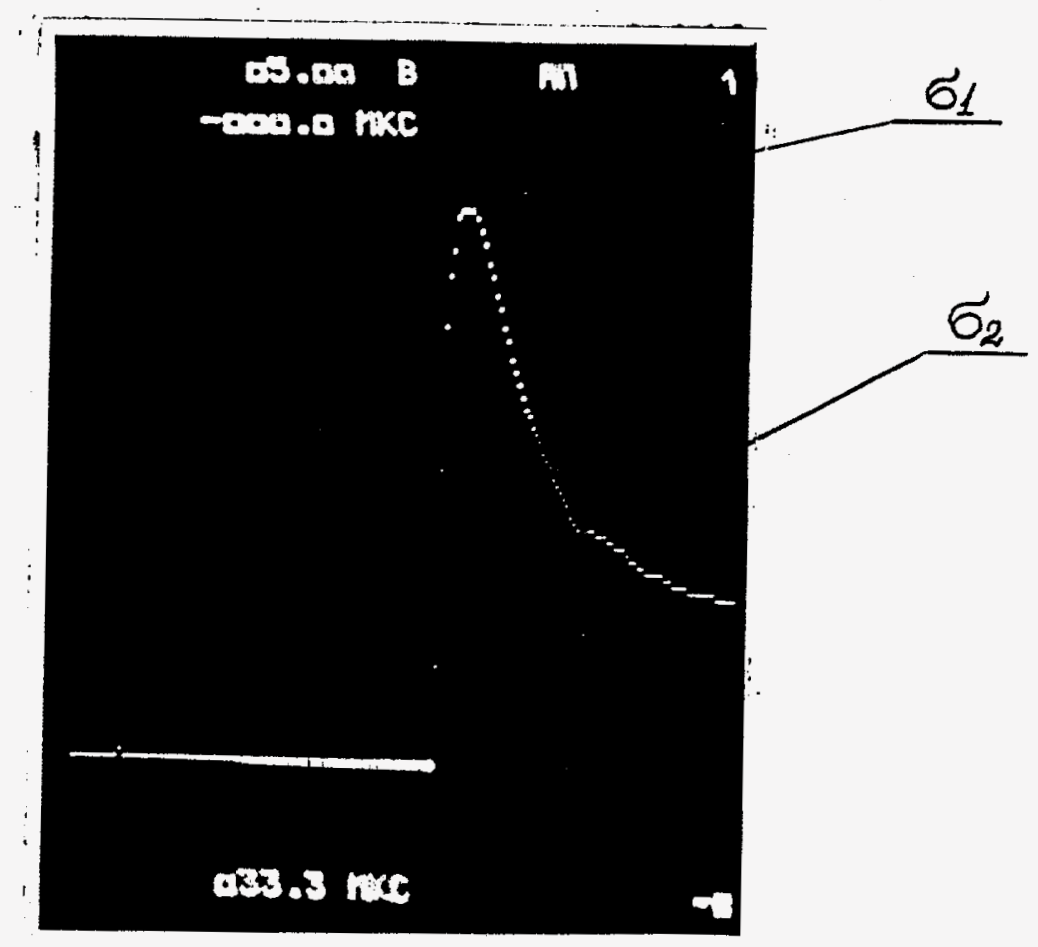

Fig.21. Oscillogram $\sigma(t)$ of the specimen-PMMA boundary. 
Sample types for metallographic ofter shock waves inpact

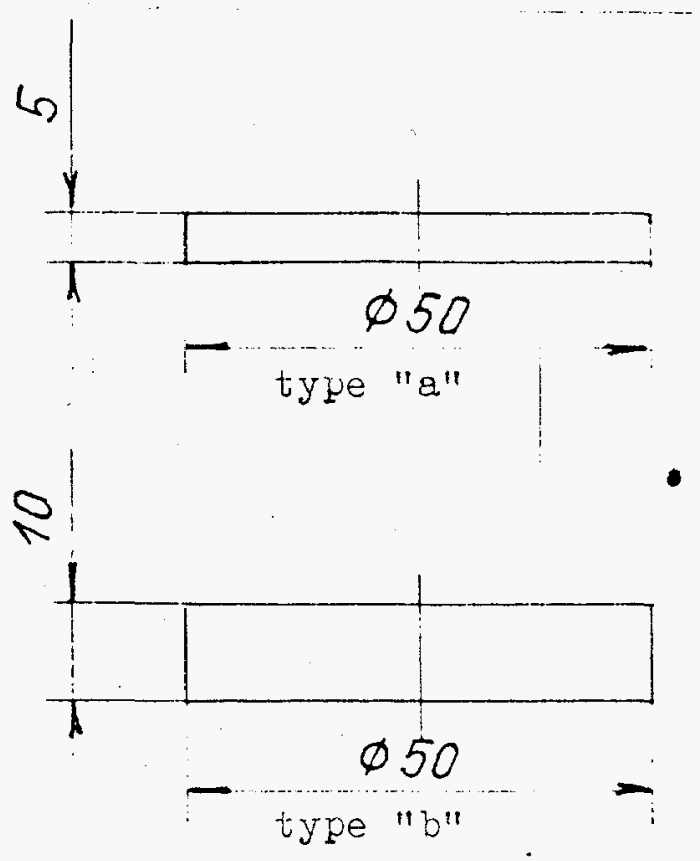

से।

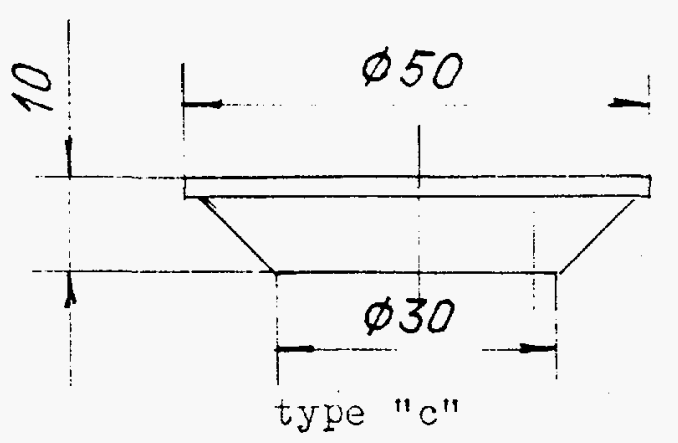

loaded surface - apwards

Pic. 22 
Spallation ciuracter of type "a" samples without heating

a)

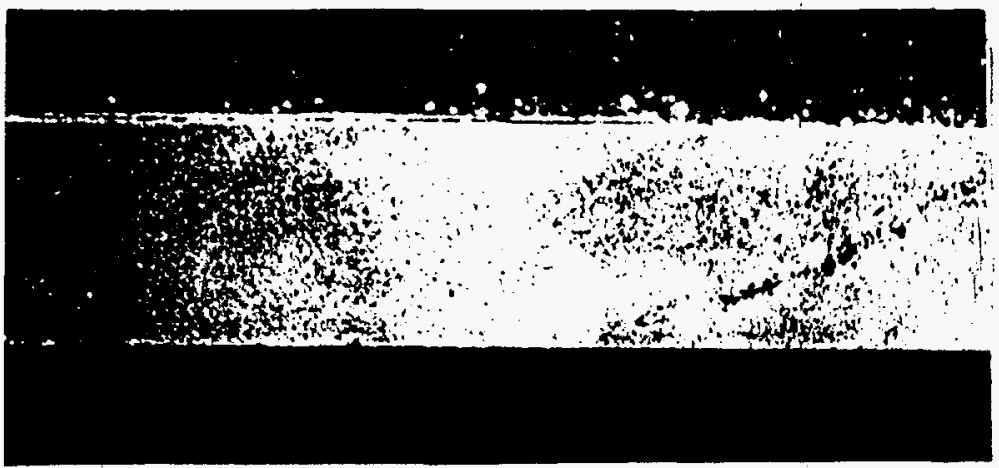

x 5 - no spallation

b)

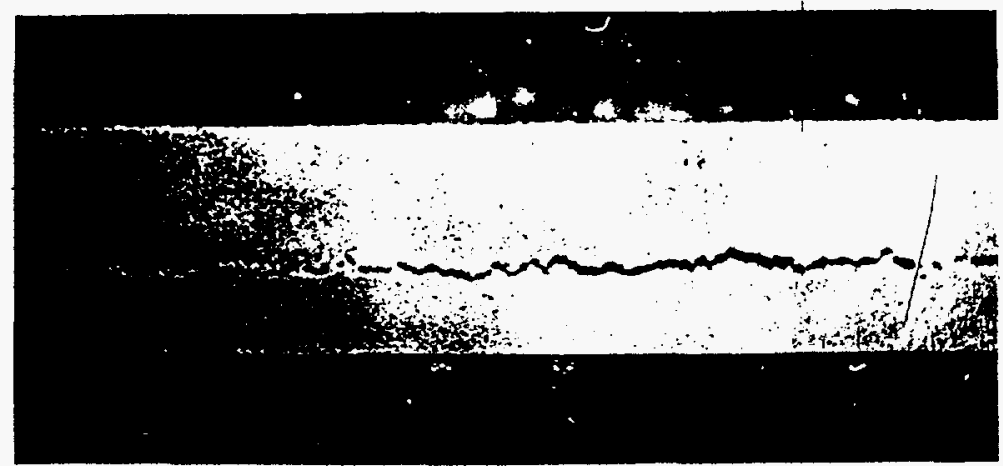

x 5 - intense inicrodestruction

c)

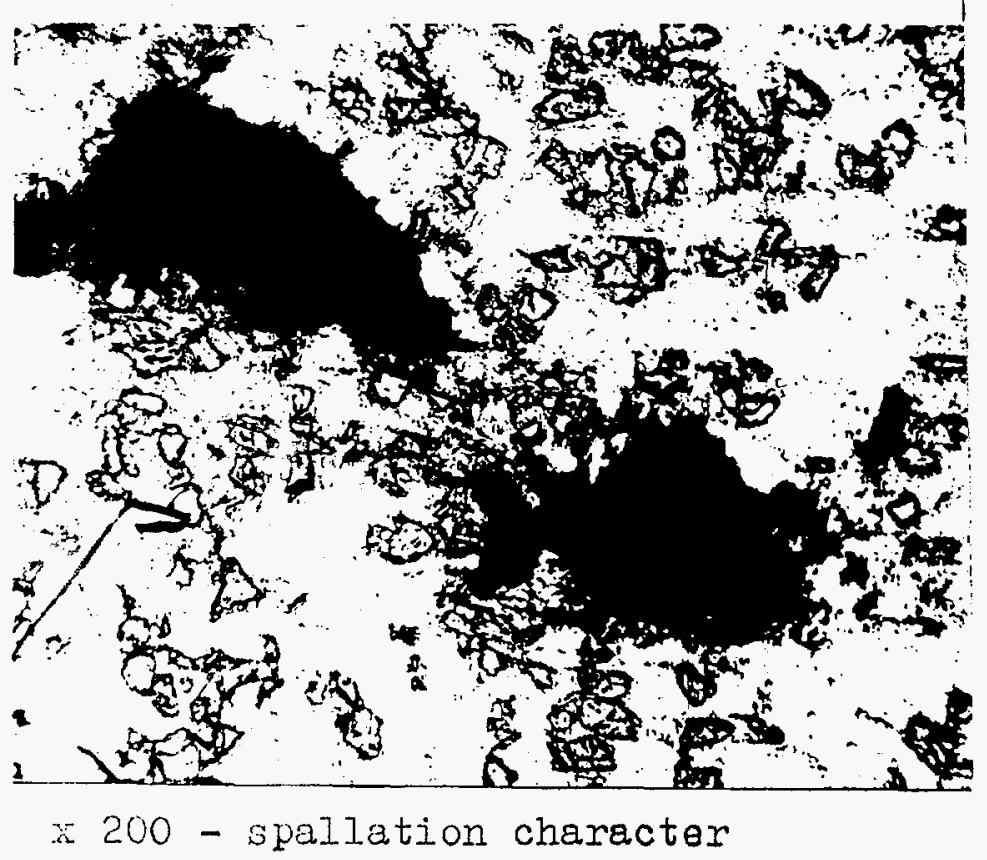


a)

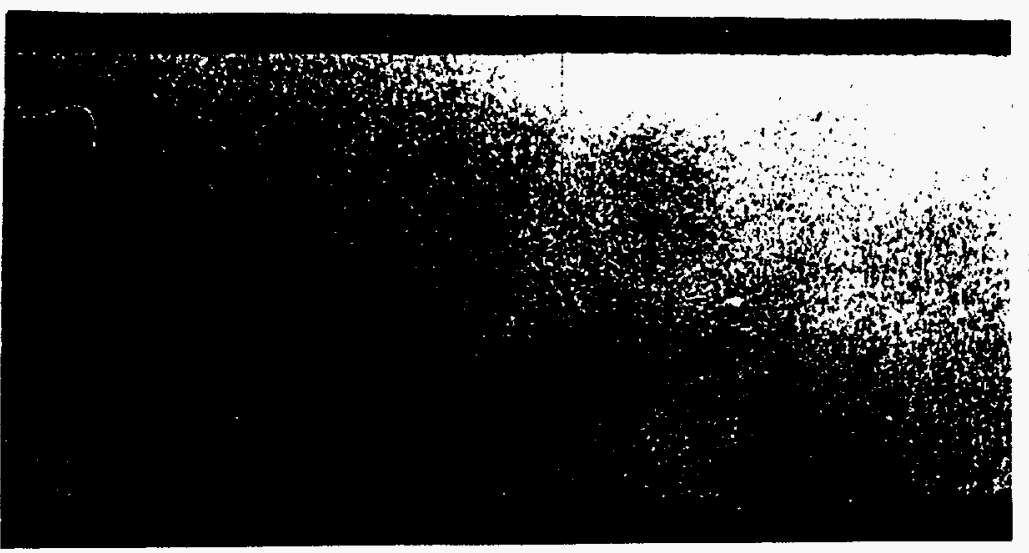

Aluminitum basis with

b)

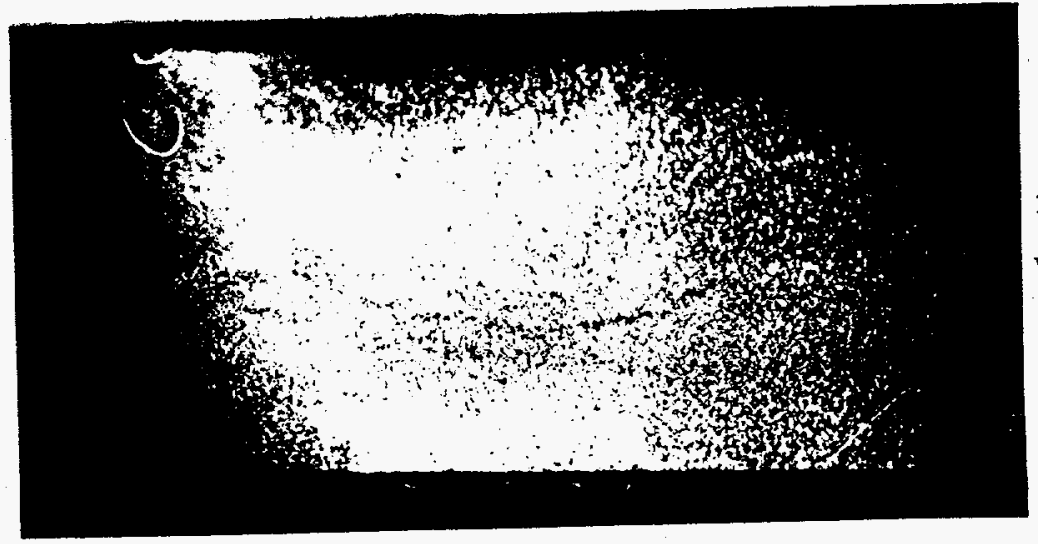

A] uninifun basis wi thout

c)
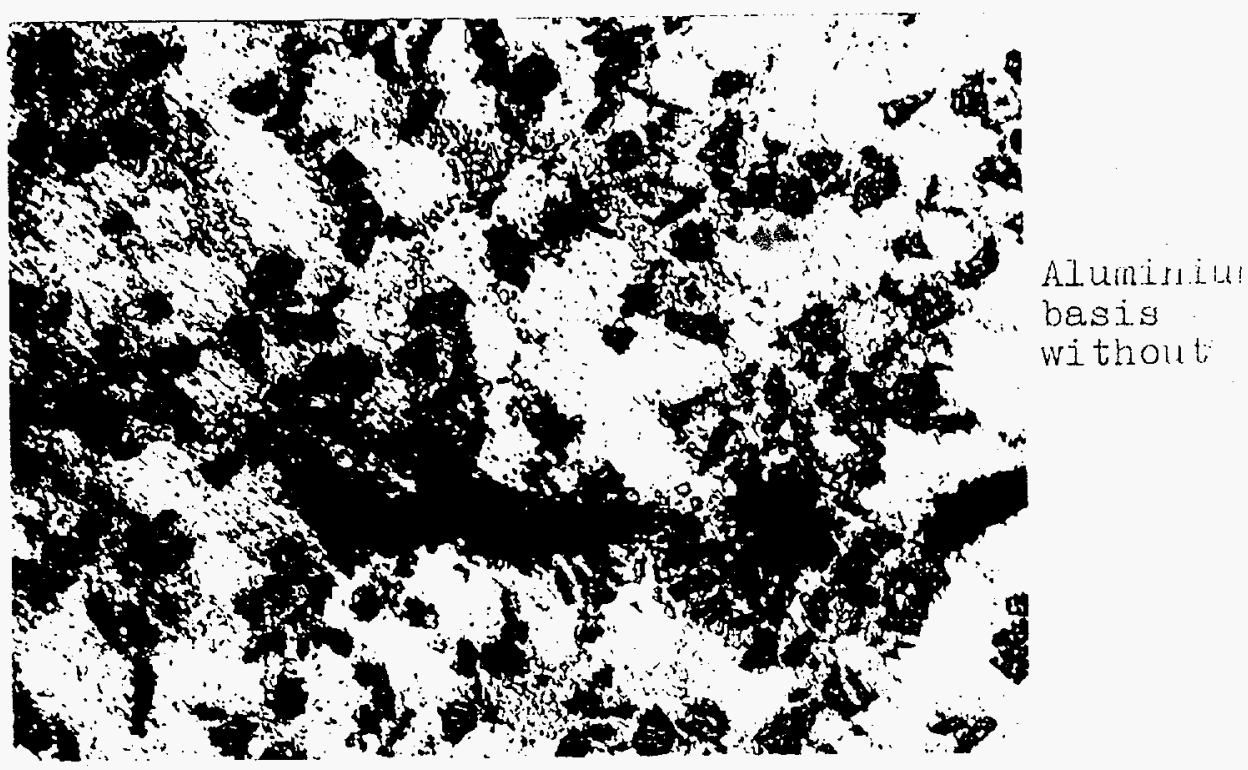

$$
+8.24
$$


Spallation destructien charecter of type "c" samplea without heating

a)

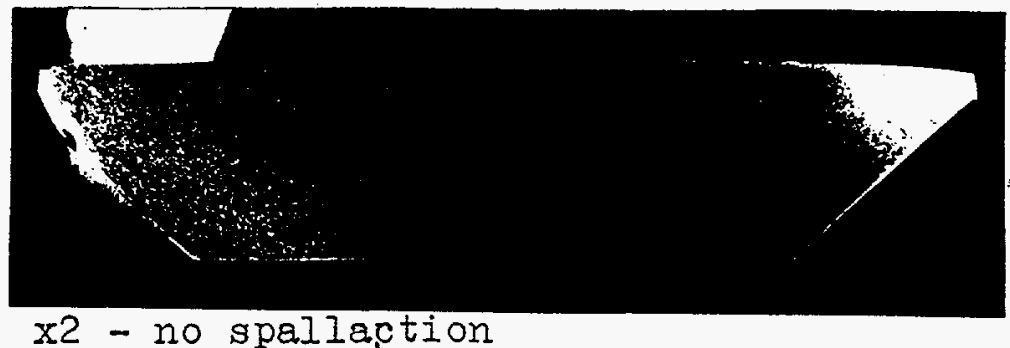

b)

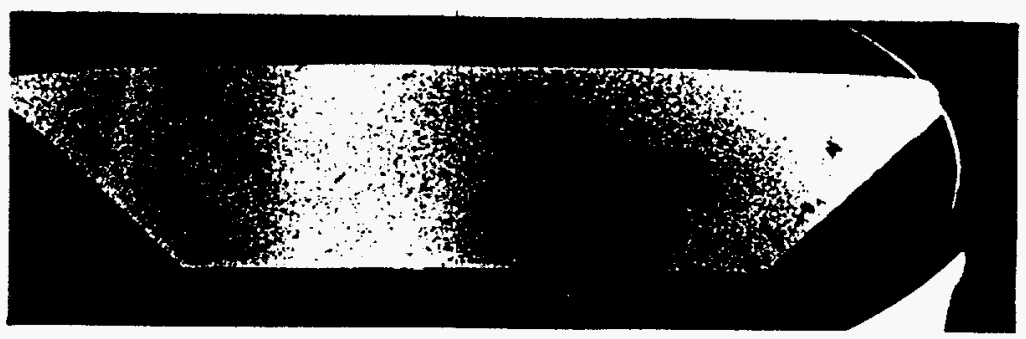

x2 - weak microdestruction

c)

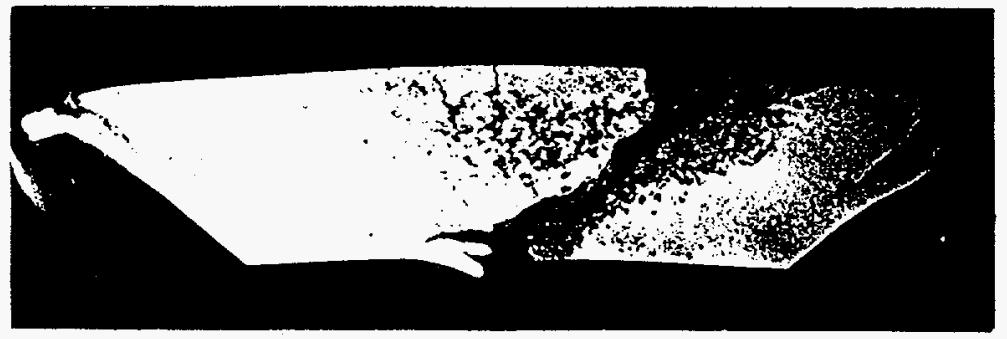

$x_{2}$ - partial spallation

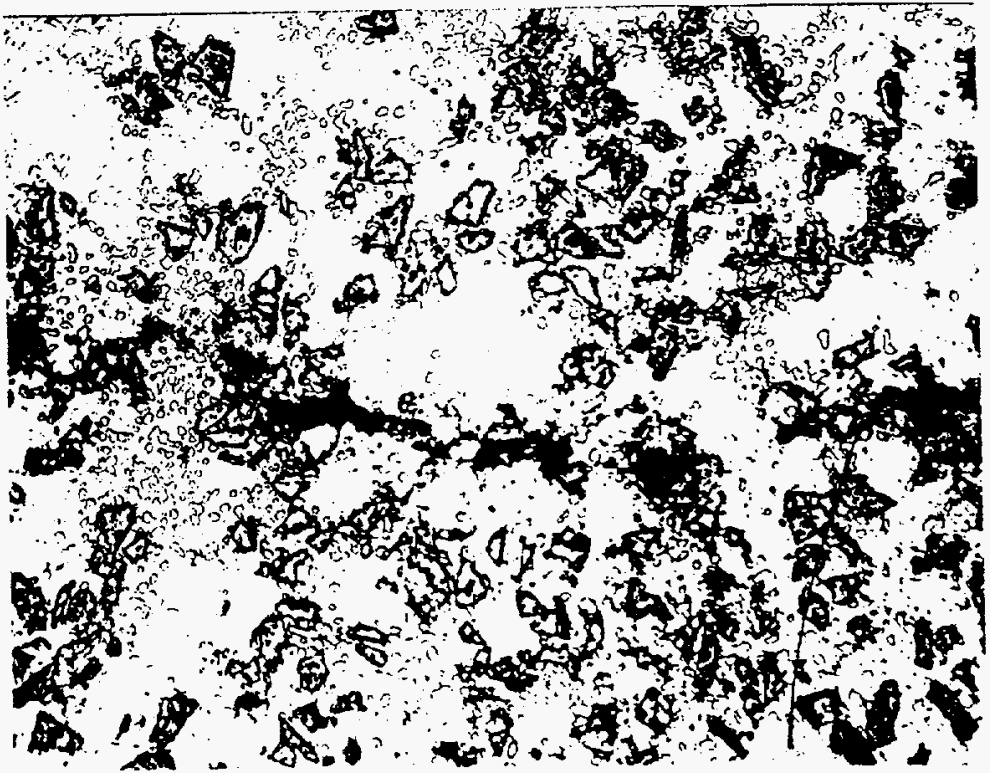

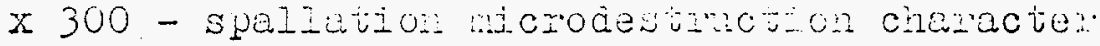


Spallation destruction character of

type "c" samples at $300^{\circ} \mathrm{C}$ heating

a)

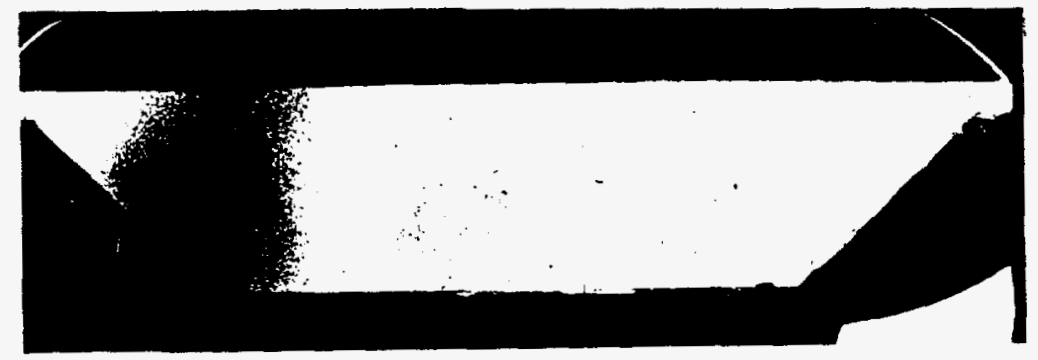

x 2 - no spallation

b)

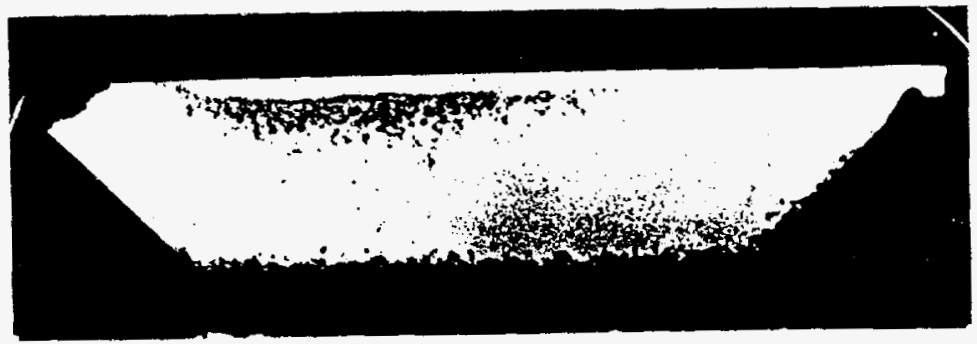

x 2 - weak microdestruction

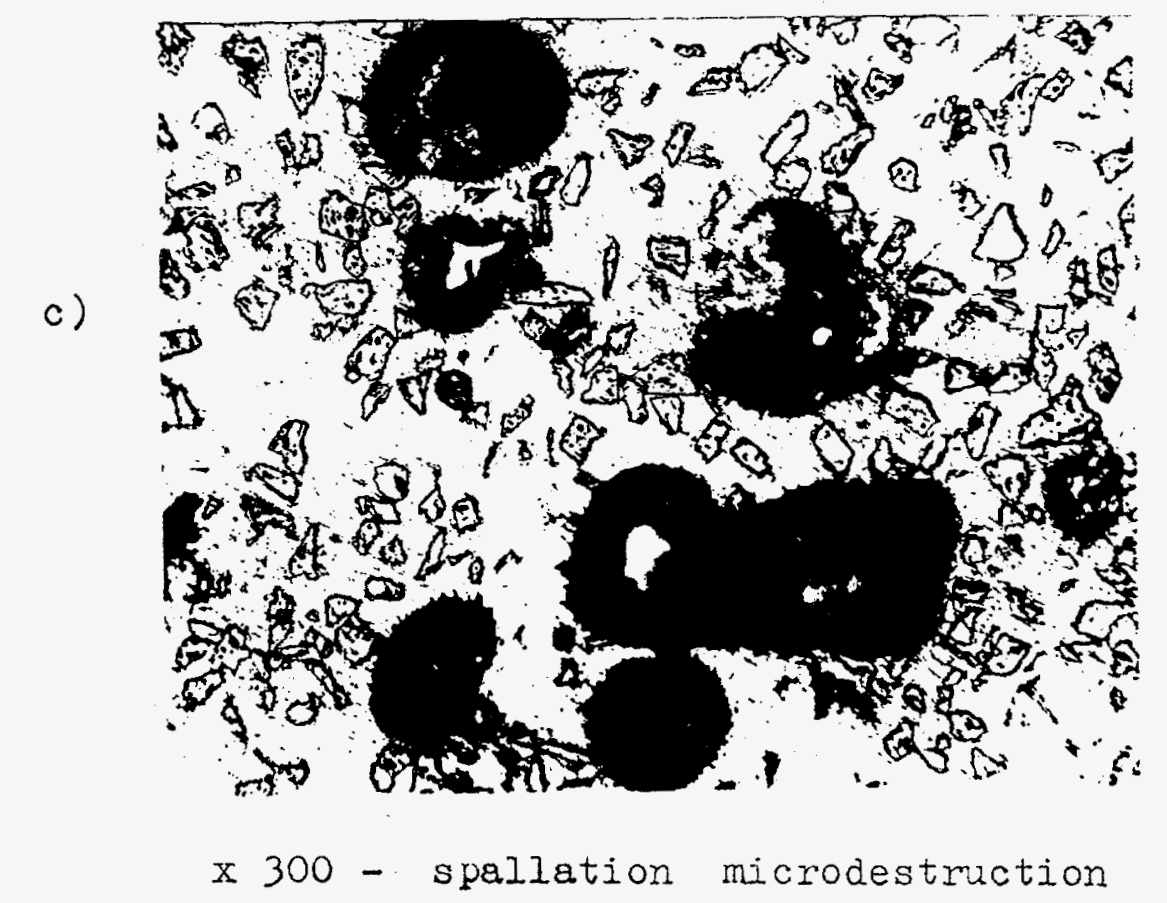

